\title{
نماذج التوازن العام العشوائية الديناميكية \\ لقياس مسار الاستدامة المالية داخل الاقتصاد المصري
}

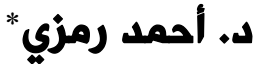

\section{مانمص}

استهدفت هذه الار اسة الكثف عن المحددات الاقتصادية للاستدامة المالية داخل الاقتصاد المصري، و انعكاسها على تصميم

وتتفيذ ومدى فعالية السياسات الاقتصادية الكلية والأداء الاقتصادي المصري، بالإضافة إلى دراسة وتحليل واختبار سلوك ومسار الاستدامة المالية في مصر • ومن خلال الخوارزم المقترح لبناء مؤشر الفائض أو العجز المالي الأولي Primary و مؤشر الفجوة الضريبية Tax Gap Indicator كمؤشرات للتنبؤ المسبق والإنذار المبكر لحالات التعثر المالي و الانحر افات في السياسة المالية، والتي تمثل حجر الز اوية عند در اسة وتحليل واختبار سلوك ومسار الاستدامة المالية داخل الاقتصاد المصري. وقد شهد الاقتصاد المصري حالات عدم الاستدامة المالية على مدار فترة الدر اسة، إلا أنها قد تكون قابلة للانعكاس في الأجل المتوسط. وللحكم الدقيق على مسار الاستدامة المالية داخل الاقتصاد المصري؛ تم استخدام نماذج التوازن العام العشوائية الديناميكية Dynamic Stochastic General Equilibrium Models ولقد تم التوصل إلى أن الاقتصاد المصري قد شهد حالات عدم الاستدامة المالية خلال فترة الدر اسة، إلا أن الاقتصاد المصري يسير في الآونة الأخيرة على الخطى الصائبة لتحقيق الاستدامة المالية، وأن حالات عدم الاستدامة المالية قد تكون قابلة للتغير في الأجل المتوسط. ولقد تم استخدام منهجية Bayesian Impulse Responses Functions IRFs للتنبؤ بمسار الاستدامة المالية داخل الاقتصاد المصري، وبناء السيناريو المرجعي و المستقبلي الذي يصور الواقع الر اهن و المستقبلي للاقتصاد المصري. الكلمات الدالة: الاستدامة المالية - نماذج التوازن العام العشوائية الديناميكية - مؤشر الفائض أو العجز المالي الأولي - مؤشر الفجوة الضريبية - استدامة الدين العام

\section{Abstract}

\section{Dynamic Stochastic General Equilibrium Models for Estimating the Path of Fiscal Sustainability in} Egyptian Economy

This study aimed to reach the economic determinants of fiscal sustainability in Egypt, and its impacts on the design, implementation, the effectiveness of macroeconomic policies, and Egyptian economic performance. This study attempt also to examine and analysis the path and behavior of fiscal sustainability in Egypt. Through the proposed algorithm for building the primary deficit indicator and tax gap indicator as indicators for pre-forecasting and early warning of financial failures and deviations in fiscal policy, which represent the cornerstone when studying and analyzing the path and behavior of fiscal sustainability in Egypt.

For accurately judge the path of fiscal sustainability in Egypt, Dynamic Stochastic General Equilibrium Models have been used to interpret the Government Intertemporal Budget Constraint, the empirical results clearly indicate that the Egyptian economy suffered from cases of fiscal unsustainability over the study period, but it has recently been following the right steps to achieve fiscal sustainability, and that cases of fiscal unsustainability may be reversible in medium term.

Bayesian Impulse Responses Functions IRFs methodology has been used to predict the path of fiscal sustainability in Egypt, and to build a reference and future scenario that depicts the current and future reality of the Egyptian economy.

Keywords: Fiscal Sustainability - Dynamic Stochastic General Equilibrium Models - Primary Deficit Indicator - Tax Gap Indicator - Debt Sustainability 


\section{1-الإطار التمهيدي للاراسة}

تحظى ظاهرة الاستدامة المالية باهتمام بالغ سواء من جانب الباحثين أو صانعي السياسة لما لها من

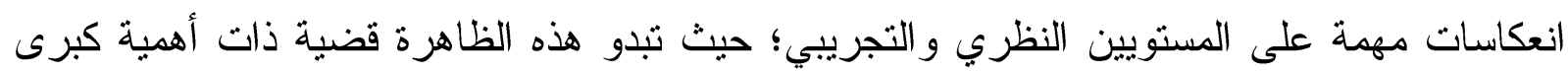
لتأثير ها على تصميم وتتفيذ ومدى فعالية السياسات الاقتصادية الكلية في الآجال الزمنية المختلفة، بالإضافة إلى ذلك تعتبر الاستدامة المالية ميزان الحرارة الذي يقيس قوة اقتصاد ما، ومدى قدرته على استيعاب الصدمات الاقتصادية المختلفة. وعلى الرغم من غياب المعايير و القو اعد المحددة للاستدامة المالية، إلا لإهي أن العديد من الدراسات - التي حاولت اختبار ظاهرة الاستدامة المالية - قد استخدمت منهج التوازن الزمني لقيد الموازنة الحكومية؛ لقياس العلاقة التوازنية طويلة الأجل بين تيار المدفوعات من الإنفاق

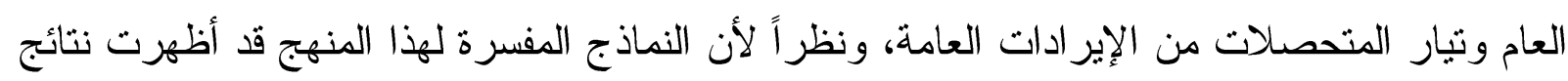

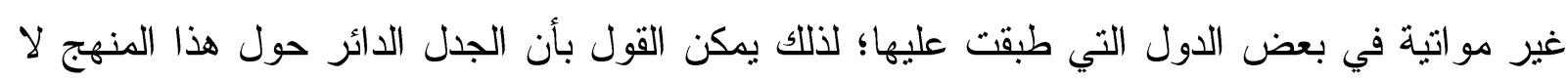

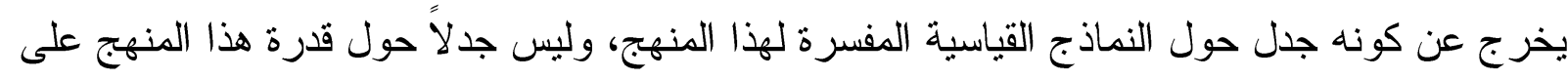
اختبار وجود ظاهرة الاستدامة المالية في اقتصاد ما. وفي ظل تعدد الأسباب المفسرة لتحقيق اقتصاد ما

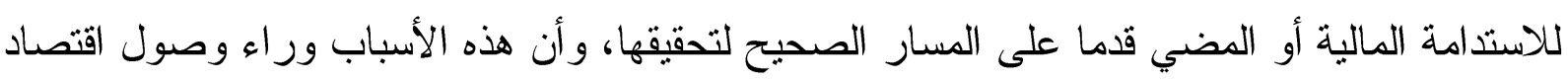
دولة ما لمرحلة الاستدامة المالية يمكن تفسير ها بو اسطة تحليل خصائص البيئة الاقتصادية للاولة، ومدى استجابة السياسات الاقتصادية الكلية من قبل السلطات النقدية و المالية داخل الاقتصاد للتغير ات في مسار ات التو ازنات الاقتصادية؛ لللك تتجه هذه الدراسة إلى الكشف عن المحددات الاقتصادية للاستدامة المالية داخل الاقتصاد المصري، والتي تمثل حجر الزاوية عند دراسة وتحليل واختبار سلوك ومسار الاستدامة المالية في مصر خلال فترة الدراسة من عام 1990م إلى عام 2018م. بات واضحا بحلول عام 2016م عدم التناسق بين الطريقة التي يتم بها وضع السياسات الاقتصادية الكلية المطبقة داخل الاقتصاد المصري مع طريقة إدارة معدل الصرف، الأمر الذي نجمت عنه بيئة اقتصادية غير مستقرة؛ ازدادت بداخلها التقلبات في معدل الصرف الحقيقي في ظل نظم معدلات الصرف الصف المختلفة المطبقة داخل الاقتصاد المصري، وانخفضت فعالية السياسة النقدية وارتفعت مستويات العجز المالي؛ مما أدى إلى زيادة تكلفة المعاملات وضعف القدرة التتافسية للصناعات الوطنية. وهو الأمر الذي انعكس في شكل استنز اف لمستوى صافي الاحتياطيات الدولية المحتفظ به من قبل السلطات النقدية، و انخفاض معدلات النمو الاقتصادي والاستثمار و النوظف و الناتج، وارتفاع معدلات التضخم وتراكم 
مستويات الدين المحلي الإجمالي إلى نسب يصعب على الاقتصاد المصري الاستمر ار في تحملها، ولقد كان نتاجاً منطقياً لذلك أن يوافق المجلس التتفيذي لصندوق النقد الدولي في نوفمبر 2016م على تقديم مساعدة مالية لمصر من خلال اتفاق للاستفادة من "تسهيل الصندوق الممدد" EFF بقيمة 8.59 مليار وحدة حقوق سحب خاصة"، أي حوالي 12 مليار دولار أمريكي؛ ليجد الاقتصاد المصري نفسه أمام سيناريو لم يتحقق منذ 16 عاما وهو تحقيق فائضاً أولياً في المو ازنة العامة للاولة يصل إلى 4.66 مليار جنيه بنسبة 0.1\%، وذلك عندما انخفض العجز الكلي للموازنة العامة كنسبة من الناتج المحلي الإجمالي من 12.3\% عام 2016 م إلى \%.7\% مام 2018 م.

في ضوء ما سبق تتلخص مشكلة الدراسة في محاولة الإجابة على التساؤلات التالية: هل العجز في الموازنة العامة داخل الاقتصاد المصري مستداماً؟ • إلى أي مدى يساهم التحرك نحو برنامج الإصلاح الاقتصادي المصري إيجابياً في مضي الاقتصاد المصري قدماً صوب تحقيق الاستدامة المالية؟". وتتطوي الدراسة على فرضية رئيسة مفادها: "من المنوقع أن يشهر الاقتصاد المصري حالات عدم الاستدامة المالية على مدار فتزة الدر اسة، إلا أن برنامج الإصلاح الاقتصادي المصري قد يساهم إيجابياً في جعل حالات عدم الاستدامة المالية قابلة للانعكاس في الأجل المتوسط". ويتمثل هدف الدراسة الرئيس في اختبار مدى صحة الفرضية السابقة، ويتفرع من هذا الهدف عدد من

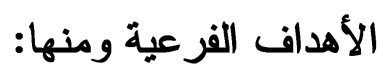
- - الكثف عن المحددات الاقتصادية للاستدامة المالية داخل الاقتصاد المصري، وانعكاسها على تصميم وتتفيذ ومدى فعالية السياسات الاقتصادية الكلية والأداء الاقتصادي المصري، - Government Intertemporal استخدام أسلوب المحاكاة لقيد الموازنة الحكومية الزمني Budget Constraint

$$
\text { الأساسي لهذا المنهج، }
$$

Dynamic Stochastic General استخدام نماذج التوازن العام العشوائية الديناميكية Equilibrium Models الاقتصاد المصري. 
- - كما تهدف الدراسة إلى التتبؤ بمسار الاستدامة المالية داخل الاقتصاد المصري، وذلك بهدف بناء السيناريو المرجعي و المستقبلي الذي يصور الو اقع الراهن للاقتصاد المصري، وذلك من

خلال استخدام منهجية Bayesian Impulse Responses Functions IRFs.

وفيما يخص إطار الدر اسة فسوف يتم بناء هيكل نظري لأبعاد مشكلة الدراسة و أهدافها، وسيتم الاعتماد في بناء الهيكل النظري على وصف ما هو قائم من تصورات نظرية في تقسير مسار الاستذامة الاستدامة المالية داخل الاقتصاد المصري، و تتبع الدر اسة منهجاً يستند إلى النظرية الاقتصادية، وسيتم مزج الهيكل النظري بالواقع العملي بتصميم خوارزم جديد مقترح لبناء مؤشر الفائض أو العجز المالي الأولي Sax Gap Indicator ومؤشر ات للتنبؤ المسبق Primary Deficit Indicator و الإنذار المبكر لحالات التعثر المالي والانحر افات في السياسة المالية، والتي تمثل حجر الزاوية عند در اسة وتحليل و اختبار سلوك ومسار الاستدامة المالية داخل الاقتصاد المصري. وفي محاولة من الباحث لسد أوجه التتاقض والاختلاف بين المناهج المفسرة للاستدامة المالية، و الحكم الدقيق على مسار الاستدامة المالية داخل الاقتصاد المصري، تتجه الدراسة إلى استخدام منهج النوازن الزمني لميزان وتسعى إلى تفسيره باستخدام نماذج التوازن العام العشوائية الديناميكية DSGE Models.

\section{2- المفاهيم المختلفة للاستدامة المالية في الأدبيات الاقتصادية}

ينظر - عادة - إلى مستويات عجز الموازنة العامة المقبولة اقتصاديا" على أنها ظاهرة صحية في العديد من الاقتصاديات الناشئة و المتقدمة على حد سواء، وذلك على النقيض تماماً من إصابة إحدى هذه الاقتصادات بمرض المستويات غير المقبولة من العجز الدائم في الموازنة العامة. إذ يعكس هذا النوع من العجز قصور أو ضعف البنية الهيكلية للاقتصاد المعني. فالسبيل لتمويله قد يكون محفوفاً بالعديد من المخاطر، و التي منها على سبيل المثال: ارتفاع معدلات التضخم، و الزيادة التر اكمية في حجم الديون الداخلية والخارجية، وهو الأمر الذي ينصرف في نهاية المطاف إلى إهدار حق الأجيال القادمة التي 
سيلقى على كاهلها عبء الديون التي استخدمتها الأجيال الحاضرة في تمويل عجز الموازنة العامة و انخفاض مستوى معيشتهم 1.

وقد انتقد العديد من الاقتصاديين في الآونة الأخيرة التفرقة بين أنواع العجز في الموازنة العامة على هذا النحو السابق. إن هذه المخاطر السابق الإشارة إليها هي التي رفعت الأصوات الداعية إلى ضرورة التفرقة بين القدرة وعدم القدرة على تمويل عجز الموازنة العامة. فأياً كان نوع العجز فإن حجمه و استمر اره لفترة تبدو غير قصيرة نسبياً يفتح أبو اب الثك نحو مدى قدرة الاقتصاد على خدمة وتمويل هذا العجز؛ ومن ثم اتجهت الدر اسات التطبيقية الحديثة في هذا المجال إلى اختبار وضع الاستدامة المالية داخل الاقتصاد المعني؛ لتصميم وتقييم السياسات الاقتصادية الكلية الحالية و المستقبلية الر امية إلى إحداث توازن الموازنة العامة، حيث بات الحديث عن تحديد نوع العجز وبحث سبل تمويله غير ذي جدوى. وبالنظر إلى الأدبيات التي تناولت مفهوم الاستدامة المالية من حيث التعريف يتضح أن هناك قدراً كبيراً من عدم الاتفاق بخصوص هذا المفهوم، ويرجع ذلك إلى ضيق، أو اتساع نطاق المفهوم المستخدم للتعبير عن الاستدامة المالية، وفيما يلي استعر اض لبعض أمثلة هذا التباين:

يشير مصطلح الاستدامة المالية Fiscal Sustainability - كما استخدمه (Adedeji, 2001) - إلى الحالة التي تتم فيها المحافظة على تمويل الاختلالات في الموازنة العامة لاقتصاد ماتحت مظلة السياسات الاقتصادية الحالية، دون الحاجة إلى تغيير جذري في هذه السياسات أو دون أن تلحق هذه السياسات الاقتصادية المطبقة أزمات بالاقتصاد محل الدر اسة2.

وحدد صندوق النقد الدولي في عام 2002م الجوانب الأساسية لتحقيق الاستدامة الاقتصادية والتي نم حصر ها في ثلاثة تقسيمات مختلفة، وهي:

\author{
الاستدامة الخارجية External Sustainability، \\ الاستدامة المالية Fiscal Sustainability، \\ استقرار القطاع المالي Financial sector stability.
}

1 Özer, M. and Coşkun, I. O., "Sustainability of Turkish fiscal deficit in the post - crisis period", Mibes Transactions International Journal, Vol.5, No.2, Greece, 2011, p 67.

${ }^{2}$ Adedeji, O. S., "The Size and Sustainability of Nigerian Current Account Deficit", International Monetary Fund, Working Paper Series, WP No. 01/87, 2001, P4. 
وفيما يخص الاستدامة المالية فلقد عرفها صندوق النقد الدولي على أنها: قدرة الدولة على تمويل العجز في الموازنة العامة للدولة من خلال تدفقات الديون الداخلية والخارجية دون الحاجة إلى إحداث تغيرات جذرية في السياسات الاقتصادية المطبقة؛ مما يؤدي إلى زيادة التوقعات المستقبلية نحو إمكانية إحداث توازن الموازنة العامة في الأجل المتوسط، وما يرتبط به من اختيار نسبة الدين العام المحلي إلى الناتج المثلى لتحقيق هذا التوازن 3.

ويرى (Burnside, 2003)، و هو من أنصسار المفهوم الواسع في تعريف الاستدامة، أن المفهوم الموسع للاستدامة المالية يبدأ أولاً من ضرورة تعريف اصطلاح الاستدامة Sustainability و الذي ينصرف إلى الحالة التي يمكن عندها الحفاظ على مستوى معين لأجل غير مسمى. وفي سياق هذا المفهوم العام فإن الاستدامة المالية تعني "إمكانية استمر ار السياسات الاقتصادية الجارية والسلوك الخاص الحالي دون أن يستبع ذلك إجراء تحولات جذرية أو توقف مفاجئ للسياسات الاقتصادية المطبقة حاليا (على سبيل المثال: اتباع سياسات نقدية أو مالية أكثر صارمة بطريقة مفاجئة قد نؤدي إلى حدوث كساد كبير)، أو بدون يؤدي ذلك إلى حدوث أزمة" (على سبيل المثال: زيادات حادة في معدلات الفائدة، نضوب مفاجئ في صافي الاحتياطيات الدولية، انهيار مفاجئ لمعدل الصرف الأجنبي، وبما يؤدي إلى ضعف قدرة الاقتصاد على خدمة الالتزامات الداخلية والخارجية)؛. ولن نجد نبايناً كبير المصطلح الاستدامة المالية بين أنصار المفهوم الموسع إذا انتقلنا إلى تعريف (Shastri, S., et.al., 2018)، حيث تعرف الاستدامة المالية على أنها قدرة الدولة الحالية و المستقبلية على الوفاء بالتز اماتها المالية وتغطية أعباء ديونها دون الحاجة إلى إعادة الجدولة أو تر اكم تلك الأعباء أو إجر اء تعديلات جذرية على السياسات الاقتصادية المطبقة لتحقيق التوازن المستقبلي بين النفقات و الإير ادات العامة5.

ومما سبق يمكن القول بأن المفهوم الموسع للاستدامة المالية يستبعد الحالة التي تكون فيها إعادة هيكلة الديون و أولويات الإنفاق وسبل تمويلها ضرورية بالفعل، كما لا يندرج تحت مظلته الحالة الذي يحتفظ فيها الاقتصاد المعني بتر اكم الديون لأجل غير مسمى بشكل أسرع من نمو قدرته على خدمة هذه الديون،

3 The Policy Development and Review Department, "Assessing Sustainability", International Monetary Fund, Working Discussion Papers, 2002, P7.

${ }^{4}$ Burnside, C., "Theoretical Prerequisites for Fiscal Sustainability Analysis", manuscript -University of Virginia, July 2003, p 1.

5 Shastri, S., et.al., "Fiscal Sustainability in Major South Asian Economies: Evidences from Panel Data Analysis", Journal of Economic Cooperation and Development, Vol. 39, No. 2, 2018, PP 69 - 73. 
كما يقر بعدم سير الاقتصاد على مسار الاستدامة المالية الصحيح إذا كان يعيش بأكثر من إمكانياته من خلال نز اكم الديون مع العلم أنه ستكون هناك حاجة ملحة لسياسات انكماثية صـارمة لخدمة هذه الديون. على الجانب الآخر لجأ صندوق النقد الدولي إلى استخدام المفهوم الضيق للاستدامة المالية حينما عرفها على أنها الحالة التي يتم فيها الحفاظ على قبد الموازنة الحكومية المؤقتة عبر الفترات الزمنية المختلفة Government Intertemporal Budget Constraint وبما يحقق الاستقرار المنشود في نسبة الدين العام المحلي إلى الناتج؛ بهدف ضمان السلامة الاقتصادية لمستويات الدين العام المحلي الإجمالي

(Alvarado, Izquierdo, and Panizza, ويظر إلى مفهوم الاستدامة المالية كما استخدمه كل من (2004 على أنه العجز أو الفائض الأولي في الموازنة كنسبة من الناتج المحلي الإجمالي و الذي يؤدي إلى استقرار الدين العام المحلي الإجمالي كنسبة من الناتج المحلي الإجمالي. وهما من أنصار المفهوم الضيف في تعريف الاستدامة المالية. والذي يمكن التعبير عنه من خلال الثكل الدالي التاليج: $[R E V-G]_{t} / G D P_{t}=g k ; k=\sum_{i=0}^{\infty} d_{t-i} / \sum_{i=0}^{\infty} G D P_{t-i}$

كما يعرف أنصار المفهوم الضيق ومنهم (Khadan, 2019 ) الاستدامة المالية تارة على أنها إلى قدرة الحكومات على الوفاء بقيود الموازنة الحكومية المؤقتة IBCSا، وتارة أخرى على أنها قدرة الاقتصاد على توليد فو ائض مالية كافية في الموازنة مستقبلا لتغطية الديون المتر اكمة ومدفوعات الفوائد المرتبطة بالعجز المالي في الفترات الحالية؛ محققاً الاستقرار المنشود في نسبة الدين العام المحلي الإجمالي إلى الناتج المحلي الإجمالي وبالنظر إلى العرض السابق يتضح أن مفهوم الاستدامة المالية يتباين من مؤلف لآخر، ونحو تحليل أكثر شمو لاً لهذه المفاهيم السابقة يتضح أن الجدل الدائر حول مفهوم الاستدامة المالية لا يخرج عن كونه جدل حول المنهج المستخدم في التعريف، وليس جدلاً حول مضمون الاستدامة المالية. فلقد ركز أنصار المفهوم الو اسع للاستدامة المالية على الحالة العامة للاقتصاد الذي تتحقق بداخله الاستدامة المالية، وعلى الجانب

6 The Policy Development and Review Department, "Assessing Sustainability", Op. cit., P 2.

7 Alvarado, C., et.al., " Fiscal Sustainability in Emerging Market Countries with an Application to Ecuador", Inter-American Development Bank, WP No. 511, 2006, PP 8 - 9.

8 Khadan, J., " Fiscal Sustainability in the Caribbean: An Econometric Analysis ", Inter-American Development Bank, Working Paper Series, WP No. 1014, 2019, P 3. 
الآخر استخدم أنصار المفهوم الضيق للاستدامة المالية بعض المؤشرات الاقتصادية والتي يمكن من خلالها الحكم على وضع الاستدامة المالية داخل اقتصاد ما. ومما سبق يمكن صياغة المفهوم الثامل للاستدامة المالية و الذي يجمع بين وجهتي النظر السابق عرضهما

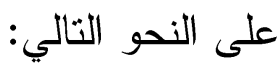

" تعرف الاستدامة المالية على أنها قدرة الدولة على تمويل العجز في الموازنة العامة من خلال مصادر التمويل المتاحة دون الحاجة إلى إحداث تغيرات جذرية في السياسات الاقتصادية المطبقة، وبما يؤدي إلى زيادة التوقعات المستقبلية نحو الحفاظ على حق الأجيال القادمة و التي كان سيلقى على كاهلها عبء الديون الداخلية والخارجية التي استخدمتها الأجيال الحاضرة في تمويل هذا العجز، ويمكن الحكم على هذه القدرة من خلال تخفيف حدة التقلبات وتحقيق الاستقرار في الدين العام المحلي الإجمالي إلى الناتج

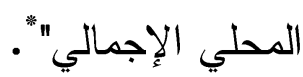

إن مفهوم الاستدامة المالية يتداخل مع ظواهر ومفاهيم أخرى، مثل: الملاعة المالية Fiscal solvency، و الاختلال المفرط Excessiveness Imbalance، ولقد تتاولت العديد من الدراسات المالية هذه المفاهيم السابقة على أنها مثر ادفات لمصطلح واحد وهو : الاستدامة المالية، ولكن الأدبيات الحديثة في هذا المجال قد تتاولت هذا التذاخل بين المفاهيم السابقة، و أكدت على وجود ثمة خلاف بين هذه المصطلحات على الرغم من التداخل بينهما" "، وذلك على النحو التالي: يعتبر مصطلح الملاءة المالية حالة خاصة من مفهوم الملاءة solvency: و الذي يشير إلى القدرة على الوفاء بالديون حال استحقاقها، وتتحقق الملاءة المالية لاقتصاد ما إذا كانت القيمة الحالية المخصومة PDV للديون الجارية و المستقبلية

* ت تم إعداد هذا المفهوم بمعرفة الباحث.

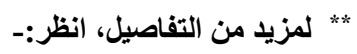

- Artus, P., "How Has the Fiscal and External Solvency of Spain, Italy and Portugal Performed Since the Start of the Crisis", Natixis Economics Research, Working Paper No. 521, France, 2002, pp 1-8.

- Burnside, C., "Theoretical Prerequisites for Fiscal Sustainability Analysis", Op. cit., P 1. 
تقل عن أو تتساوى مع القيمة الحالية المخصومة للفو ائض المالية المتولدة في الفترة الجارية و المستقبلية مخصوما منها الديون عن العام المنصرم ومدفوعات الفائدة الخاصة بها، $\sum_{i=0}^{\infty}(R V-G E)_{t+i} / \prod_{j=1}^{i}\left(1+r_{t+j}\right)$ ويمكن التعبير عن هذا المفهوم من خلال الثكل الدالي التالي:

$\sum_{i=0}^{\infty} \frac{D_{t+i}}{\prod_{j=1}^{i}\left(1+r_{t+j}\right)} \leq \sum_{i=0}^{\infty} \frac{\left(R V_{t+i}-G E_{t+i}\right)}{\prod_{j=1}^{i}\left(1+r_{t+j}\right)}-\left(1+r_{t}\right) D_{t-1}$

و إن كان مفهوم الملاءة المالية يفترض ضرورة توليد موارد ذاتية تتمثل في الفوائض المالية المتحققة مستقبلا لسداد الديون التي نم استخدامها حاليا في تمويل العجز، فإن مصطلح الاستدامة المالية لا يهنم سوى بالقدرة على تمويل هذا العجز و الحفاظ عليها، حتى ولو تم سداد هذه الديون من خلال التمويل البونزي Ponzi financing" ". أما مفهوم الاختلال المفرط فيشير إلى الحالة التي يصل فيها مقدار العجز في الموازنة العامة إلى الحدود التي لا يمكن تحملها داخل الاقتصاد أو يتعدى هذا العجز الحقيقي مقدار العجز المتنبأ به، وهي الحالة التي لا يمكن تفسير ها باستخدام نماذج الإنتاج والاستهلاك، أو الحالة التي ينحرف فيها مسار الاقتصاد عن معيار الأمثلية، ومن هنا يمكن القول بأن مصطلح الاستدامة المالية يركز على مقدار العجز الذي يمكن أن تتعايش معه السياسات الاقتصادية الحالية، بينما يركز مفهوم الاختلال المفرط على مقدار العجز في الموازنة العامة الذي لا يمكن أن تتعايش معه السياسات الاقتصادية المطبقة حاليا.

3- مناهج تفسير الاستدامة المالية في الفكر الاقتصادي

يعود التأصيل النظري لقيد الموازنة الحكومية الزمني Government Intertemporal Budget Theory of Behaviour of Consumer إلى نظرية نعظيم سلوك المستهلك Constraint Optimization الزمن في ظل قيد دخله المتاح، فإن الحكومة الرشيدة تسعى أيضا إلى تعظيم منفعتها طو ال دورة حياتها 
الاقتصادية في ظل قبد الموازنة، الذي يعني أن القيمة الحالية للإنفاق العام يجب أن تتساوى مع القيمة الحالية للإير ادات العامة'

وفي ظل هذا السباق يمكن القول بأن منهج التوازن الزمني يفترض أن الحكومة تسعى إلى تعظيم منفعتها

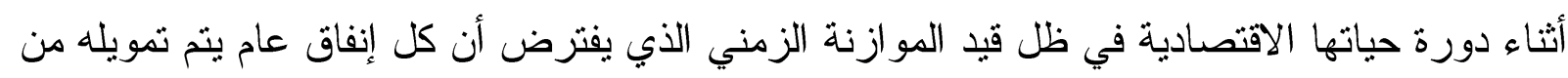

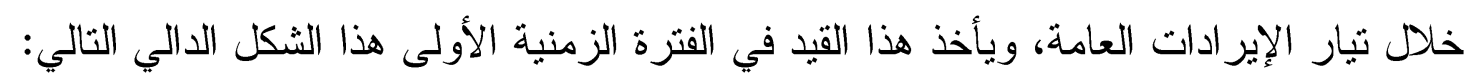
$G E_{I}=T R_{I}+B_{I}$

حيث يشير GE إلى الإنفاق العام في الفترة الزمنية الأولى التي ينم تمويلها من خلال منحصلات الإير ادات في الفترة الزمنية الأولى ,TR ، بالإضافة إلى مقدار الديون التي تقترضها الحكومة من العالم في الفترة

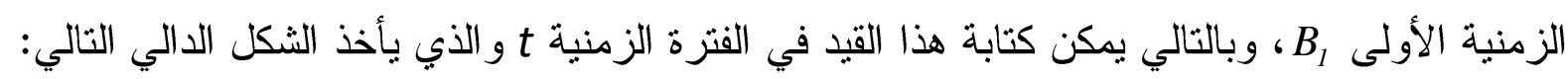
$G E_{t}+(1+r) B_{t-1}=T R_{t}+B_{t}$

يمثل خدمة هذا الدين بمعدل فائدة r، وبالتالي نم إضافته لتيار الإنفاق العام في الجانب الأيسر من المعادلة. ويمكن إعادة كتابة المعادلة رقم 2 على النحو التالي:

$G E_{t}-T R_{t}+r B_{t-1}=B_{t}-B_{t-1}$

يشير

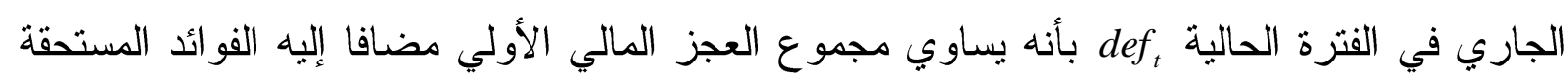
على الديون السابقة، وذلك كما يلي:

$$
d e f_{t}=G E_{t}-T R_{t}+r B_{t-1}
$$

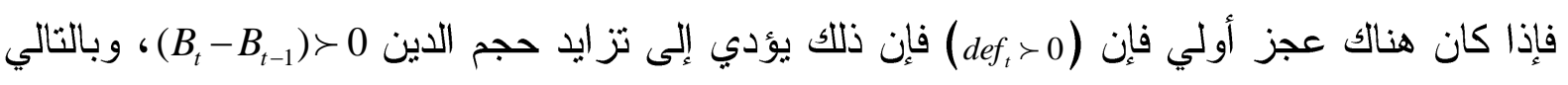
فإن

${ }^{9}$ Krueger, D., "Dynamic Fiscal Policy", University of Pennsylvania - Department of Economics, First Edition, Philadelphia, 2007, PP 59 - 60. 
السابقة. ويمكن إعادة كتابة المعادلة رقم 2 مرة أخرى في الفترة الزمنية الثانبة مرة أخرى على النحو

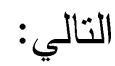

$G E_{2}+(1+r) B_{1}=T R_{2}+B_{2}$

حيث إن قيمة الدين المحلي في الفترة الزمنية الأولى يمكن أن يأخذ الثكل الدالي التالي:

$B_{1}=\frac{T R_{2}+B_{2}-G E_{2}}{(1+r)}$

وبالتعويض عن B

$G E_{1}=T R_{1}+\frac{T R_{2}+B_{2}-G E_{2}}{(1+r)}$

$G E_{1}+\frac{G E_{2}}{(1+r)}=T R_{1}+\frac{T R_{2}}{(1+r)}+\frac{B_{2}}{(1+r)}$

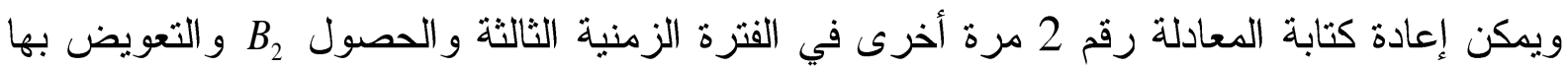
في المعادلة رقم 1 نحصل على ما يلي:

$G E_{1}+\frac{G E_{2}}{(1+r)}+\frac{G E_{3}}{(1+r)^{2}}=T R_{1}+\frac{T R_{2}}{(1+r)}+\frac{T R_{3}}{(1+r)^{2}}+\frac{B_{3}}{(1+r)^{2}}$

وبالتعميم يمكن الحصول على قيد التوازن الزمني لتحقيق الاستدامة المالية في الفترة الزمنية t وذلك

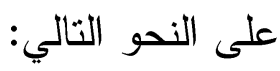

$G E_{1}+\frac{G E_{2}}{(1+r)}+\frac{G E_{3}}{(1+r)^{2}}+\ldots .+\frac{G E_{t}}{(1+r)^{t-1}}=T R_{I}+\frac{T R_{2}}{(1+r)}+\frac{T R_{3}}{(1+r)^{2}}$

$+\ldots+\frac{T R_{t}}{(1+r)^{t-1}}+\ldots+\frac{B_{t}}{(1+r)^{t-1}}$

وبافتز اض أن الحكومات في الأجل الطويل لن يكون عليها ديون، ولا لايها - أيضا - فائض مالي؛ فيمكن بالتالي اعتبار 
$G E_{1}+\frac{G E_{2}}{(1+r)}+\frac{G E_{3}}{(1+r)^{2}}+\ldots+\frac{G E_{t}}{(1+r)^{t-1}}=T R_{1}+\frac{T R_{2}}{(1+r)}+\frac{T R_{3}}{(1+r)^{2}}$

$+\ldots+\frac{T R_{t}}{(1+r)^{t-1}}$

و هكذا فإن قيد التو ازن الزمني الذي يوضح أن القيمة الحالية لتيار الإنفاق العام يجب أن تشساوى مع القيمة الحالية لتيار الإير ادات العامة، يمكن كتابته على النحو التالي:

$\sum_{t=1}^{T} \frac{G E_{t}}{(1+r)^{t-1}}=\sum_{t=1}^{T} \frac{T R_{t}}{(1+r)^{t-1}}$

وبافتراض أن الحكومات لن تموت وستعيش إلى وقت نهاية الأرض، فإنه يمكن كتابة قيد التوازن الزمني" - الذي يوضح في هذه الحالة أن كل إنفاق عام يتم تمويله من خلال تيار الإيرادات العامة، وذلك على النحو التالي:

$\sum_{t=1}^{\infty} \frac{G E_{t}}{(1+r)^{t-1}}=\sum_{t=1}^{\infty} \frac{T R_{t}}{(1+r)^{t-1}}$

و على الرغم من غياب المعايير و القو اعد المحددة للاستذامة المالية، إلا أن العديد من الدراسات - التي حاولت اختبار ظاهرة الاستدامة المالية - قد استخدمت منهج القيد الموازنة الحكومية الزمني؛ لقياس العلاقة التوازنية طويلة الأجل بين تيار الإنفاق العام وتيار الإيرادات العامة. ونظر الأن النماذج المفسرة لهذا المنهج قد أظهرت نتائج غير مواتية في بعض الدول التي طبقت عليها؛ لذلك يمكن القول بأن الجدل الدائر حول هذا المنهج لا يخرج عن كونه جدل حول النماذج القياسية المفسرة لهذا المنهج، وليس جدلاً حول قدرة هذا المنهج على اختبار وجود ظاهرة الاستدامة المالية في اقتصاد ما. وتأسيساً على ما تقدم يمكن صياغة النموذج الأساسي لمنهج التوازن قيد الموازنة الحكومية الزمني، و الذي يبدأ بصياغة قيد التو ازن الزمني من معادلة الدخل القومي، وذلك على النحو التالي:

$C_{t}=Y_{t}+B_{t}-I_{t}-(1+r) B_{t-1}$

حيث يشير C $C_{t}$ B فيشير إلى حجم الدين المتاح للفرد و الذي من الممكن أن يأخذ قيمة سالبة أو موجبة، كما يمثل حجم الديون الداخلية في الفترة السابقة والتي آن وقت استحقاقها في الفترة الزمنية الحالية مضافا إليها 
خدمة هذا الدين بمعدل فائدة r. ونظرا لأن قيد التوازن الزمني يجب الإيفاء به خلال دورة حياة الفرد الاقتصادية عبر الفترات الزمنية المختلفة، فإنه يمكن تعميم هذا القيد لكافة الأفر اد داخل المجتمع على بلى

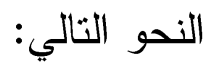

$$
B_{t}=\sum_{i=1}^{\infty} \delta_{i}\left[Y_{t}-C_{t}-I_{t}\right]+\lim _{i \rightarrow \infty} \delta_{i} B_{t} \quad ; \delta_{i}=\prod_{j=l}^{i}\left(\frac{1}{1+r_{t+j}}\right)
$$

يشير iס إلى مضروب معامل الخصم، و الذي يمكن من خلاله حساب القيمة الحالية المخصومة PDV. ويمكن إعادة كتابة المعادلة رقم 14 لتأخذ الثنكل الدالي التالي:

$(1+r) B_{t-1}=Y_{t}-C_{t}-I_{t}+B_{t}$

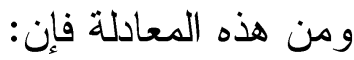

$(1+r) B_{t-1}-B_{t}=Y_{t}-C_{t}-I_{t}$

وحيث أن عجز الموازنة العامة BDt و الذي يمكن الحصول عليه من حاصل الفرق بين الإنفاق العام

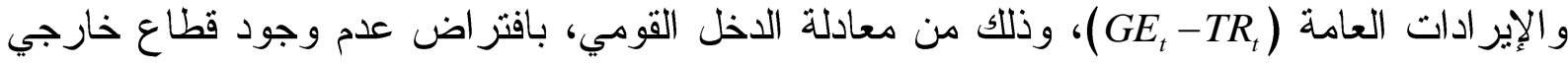

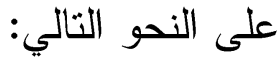

$Y_{t}-C_{t}-I_{t}=G E_{t}-T R_{t}=B D_{t}$

وبإحلال المعادلة رقم 19 في المعادلة رقم 18 يمكن الحصول على ما يلي:

$B_{t-1}+r B_{t-1}-B_{t}=G E_{t}-T R_{t}$

ويمكن إعادة ترتيب المعادلة السابقة؛ للحصول على ما يلي:

$G E_{t}+r B_{t-1}=T R_{t}+B_{t}-B_{t-1}$

وبإعتبار أن TGE تمثل تيار الإنفاق العام مضافا إليها مدفوعات خدمة الدين في الفترة السابقة

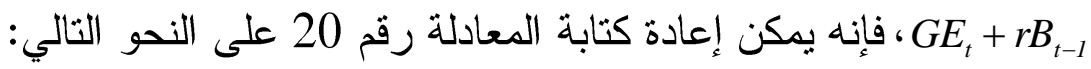

$T G E_{t}=T R_{t}+\Delta B_{t} \quad ; T G E_{t}=G E_{t}+r B_{t-1}$ 
وبالتعويض دن المعادلات رقم 15 و18 في المعادلة رقم 21، فإنه يمكن إعادة كتابة المعادلة السابقة

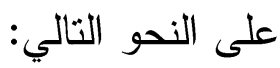

$T G E_{t}=T R_{t}+\Delta\left[\sum_{i=1}^{\infty} \frac{\left[T R_{t}-G E_{t}\right]}{\prod_{j=l}^{i}\left(1+r_{t+j}\right)}+\lim _{i \rightarrow \infty} \frac{B_{t}}{\prod_{j=l}^{i}\left(1+r_{t+j}\right)}\right]$

وبافتر اض أن الحكومات في الأجل الطويل لن يكون عليها ديون، ولا لديها أيضا فائض في الموازنة العامة للدولة ورصبد الموازنة العامة سيكون مساويا للصفر ؛ فإن حد النهايات لابد أن يؤول إلى الصفر، و عند هذه اللحظة الزمنية ستتساوى القيمة المستقبلية للإير ادات العامة دع القيمة المستقبلية للنفقات العامة ويصبح الفرق بينها و المعبر عنه بالحد الأول مساويا لقيمة ثابتة، وبالتعويض عنها بالحد الثابت ه . و تأسيسا على ذلك يمكن صياغة النموذج الأساسي لمنهج التوازن الزمني للموازنة العامة، و الذي يأخذ

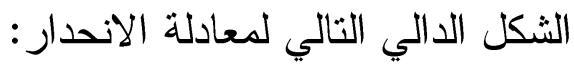

$T G E_{t}=\alpha+T R_{t}+\varepsilon_{t}$

و أياً كان النموذج القياسي المستخدم لتفسير منهج التوازن الزمني للموازنة العامة، فقد اتفق أنصسار هذا المنهج على أنه في حالة عدم وجود علاقة تساكن مشترك أو علاقة طويلة الأجل بين السلاسل الزمنية لتيار المتحصلات من الإير ادات العامة TR و وتيار الإنفاق على العام مضافاً إليها مدفوعات خدمة الدين TGE t فإن ذلك يعني عدم قدرة الاقتصاد المعني على تحقيق الاستدامة المالية؛ وهو ما يعد أحد أهم المؤشرات على معاناة هذا البلد من مرض الهشاشة الاقتصادية. و إذا كان هناك علاقة تساكن مشترك بين السلاسل الزمنية للمتغيرين أو علاقة طويلة الأجل بينهما وكان معامل انحدار التساكن المشترك مساوياً للواحد الصحيح، فإن ذلك يعني قدرة الاقتصاد على تحقيق الاستذامة المالية، أما إذا كان معامل الانحدار أصغر من الواحد فإن الاستدامة المالية سنكون ضعيفة وقابلة للانعكاس فيما بعد؛ وذلك نظر ا لنمو تيار الإنفاق العام مضافا إليها مدفوعات خدمة الدين TGE بمعدل أكبر من معدل نمو تيار

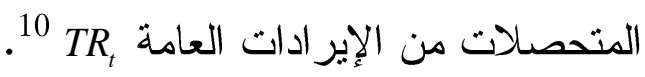

${ }^{10}$ Shastri, S., et.al., "Fiscal Sustainability in Major South Asian Economies: Evidences from Panel Data Analysis", Op. cit., P 74

- Lee, K. and Kim, H., "Fiscal Sustainability Test on Social Spending", Review of Institution and Economics, Vol.12, No.1,2018, PP 141 - 155. 
يعد التحليل السابق بمثابة تأكيداً طبيعياً على المبادئ و الركائز النظرية التي قام عليها الفكر الكلاسيكي و النيوكلاسيكي، و اللذان أقرا بمبدأ توازن الموازنة العامة المتحقق أعلاه في ظل منهج التوازن الزمني للمو ازنة العامة إذا كانت القيمة الحالية المخصومة للإنفاق الحالي و المستقبلي لا تزيد عن القيمة الحالية المخصومة لاتجاه الاخل الجاري و المستقبلي. إلا أن اعتتاق الفكر النيوكلاسيكي لمبدئي التوقعات الرشيدة و الأمتلية؛ جعل من نموذج دايموند Diamond Model المفسر الأساسي لظاهرة الاستدامة المالية والتي تم تفسير ها على أنها تحقيق التو ازن لاى الوحدات الاقتصادية المتمثلة في الأفر اد و المنشآت و الحكومة، فالأفر اد في ظل سعيهم لتعظيم المنفعة يحققون الاستدامة إذا كان هناك فو ائض في أجورهم قادرة على سداد الضر ائب (K) الأجور وأن يكون الاستثمار في الإنتاج الرأسمالي موجب بحيث أن الادخار يستطيع سداد الدين >b ثم يحقق الاقتصاد المعني الاستدامة المالية عندما يتساوى معدل الضريبة مع الإنتاجية الحدية مع العائد $\tau_{t}=f\left(K_{t}\right) \equiv(1+r) b \equiv \tau\left(K_{t}, b\right)$ الو اجب دفعه على الدين 11.

ولم يختلف كثيراً أنصار الفكر الكينزي والنماذج النيوكينزية في تفسيرهم للاستدامة المالية عن أنصار النهج الكلاسيكي و النيوكلاسيكي في استخدامهم للنماذج اليقينية التي توصلت إلى أن الاستدامة المالية تتحقق عندما يؤول الدين إلى الصفر *b، وتسدد الحكومة هذه الديون من الضرائب T، أما الاختلاف المنطقي بينهما كان لأثز السياسة المالية الدائم على إجمالي الطلب في الأجل الطويل، و الذي يؤدي إلى زيادة مستوى الدخل والثروة w ومعدل الفائدة r، وهو ما يمثل وضعاً غير مستقر في ظل النماذج النيوكينزية؛ ليجد الاقتصاد نفسه على مسار المفاضلة بين الطلب على النقود لأغر اض المضاربة و الطلب على الديون Lا، وفي ظل الإحلال الكامل بين رأس المال والدين فإن نسبة رأس المال إلى الناتج aوف تتتاسب طردياً مع العائد على رأس المال وعكسياً مع معدل العائد على الديون، وذلك وفقا

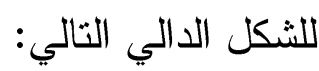

\footnotetext{
${ }^{11}$ Bagnai, A., "keynesian and neoclassical fiscal sustainability indicators with applications to Emu member countries", National Bureau Of Economic Research, NBER Working paper Series No. 8057, Cambridge, 


$$
\frac{B}{y} \prec b^{*} \equiv-\frac{\left[\frac{\tau}{1-\tau}-r w+\alpha\right] \psi+\alpha}{r} \quad ; \psi=(1-\tau) L_{1} r / L
$$

ولقد ارتكز الباحثون و المؤسسات الدولية على مبدأ سيادة اليقين التام و التوافق مع القيد الدائم للموازنة الحكومية في ظل المناهج الكلاسيكية والكينزية عند تحليل واختبار مسار الاستدامة المالية داخل الاقتصادات المتقدمة و النامية على حد سواء. وقد أولى صندوق النقد الدولي لموضوع ثقييم الاستدامة المالية داخل الدول النامية في ظل بيئة غير يقنية الأهمية المناسبة، وجعلها على رأس الموضوعات التي يناقتها الصندوق مع هذه الدول كأحد أدوات الثفافية المالية. وبدأ يطفو على السطح فكرة إدخال علم الاحتمالات في تحليل الاستدامة المالية، لتخرج إلى النور المناهج غير اليقينية لتحليل الاستدامة الماليةUncertainty Approach؛ بهدف الوصول إلى نتائج أكثر دقة وواقعية لصانعي السياسة في الدول النامية، نظر الما يسود هذه الاقتصادات من حالات عدم اليقين و الصدمات العشو ائية والتذبذبات الحادة في القاعدة الضريبية، بالإضافة إلى ضعف المرونات الخاصة بتعديل تبار الإنفاق العام. ولقد استندت الدر اسات التطبيقية الحديثة - التي اتخذت من المناهج غير اليقينية المحرك الأساسي لتحليل الاستدامة المالية - إلى مبدأ التعهد بإمكانية الدفع CPC" في تفسيرها لظاهرة الاستدامة المالية، حيث أكدت على أهمية تقدير احتمالات لنسب الدين المتوقعة في الأجل المتوسط في ظل سيناريوهات متعددة تأخذ في اعتبارها العلاقة الارتباطية بين المتغيرات المؤثزة على مستويات الدين. وفي ظل هذه المناهج غير اليقينية يسير الاقتصاد المعني على الخطى الصائبة لتحقيق الاستدامة المالية إذا كان المستوى الحقيقي لنسبة الدين العام إلى الناتج المحلي الإجمالي b أقل من أو تساوي الحدود الاحتمالية لنسبة الدين العام إلى الناتج المحلي الإجمالي bا، و التي يتم حسابها من خلال طرح أقل قيمة ممكنة لنسبة الإيرادات إلى الناتج المحلي الإجمالي $e^{m i n} t^{m i n}$ من أقل مستوى ممكن لنسبة الإنفاق العام إلى الناتج المحلي الإجمالي مرجحا بمعدل الفائدة الحقيقيr ومعدل النمو الاقتصادي و، وذلك وفقا للشكل الدالي التالي: $b \leq b^{*} \equiv\left(t^{\min }-e^{\min }\right)\left[\frac{1+g}{r-g}\right] \quad ;$ 


\section{4- مسار الاستدامة المالية داخل الاقتصاد المصري}

لقد اتضح من العرض السابق تعدد الأسباب المفسرة لتحقيق اقتصاد ما للاستدامة المالية أو المضي قدما على المسار الصحيح لتحقيقها، وأن هذه الأسباب وراء وصول اقتصاد دولة ما لمرحلة الاستدامة المالية يمكن تفسير ها بواسطة تحليل خصائص البيئة الاقتصادية للاولة، ومدى استجابة السياسات الاقتصادية الكلية من قبل السلطات النقدية والمالية داخل الاقتصاد؛ لذلك يتصدى هذا الجزء إلى استخدام منهج صندوق النقد الدولي في بناء مؤشرات التتبؤ المسبق والإنذار المبكر لحالات التعثر المالي والانحر افات في السياسة المالية، و التي تمثل حجر الزاوية عند دراسة وتحليل واختبار سلوك ومسار الاستدامة المالية داخل الاقتصاد المصري، وذلك على النحو التالي: 1/4 مؤشر الفائض أو العجز المالي الأولي

يعد مؤشر الفائض أو العزز المالي الأولي Primary Deficit Indicator نتاجاً طبيعياً للمداخل اليقينية القائمة على المزج بين الفكر النيوكلاسيكي و الفكر النيوكينزي في تقييمها للاستدامة المالية، ولقد ساق (Buiter, 1985) ستتوقف بعد فوات الأوان"، ولقد خضع هذا المؤشر لمزيد من التعديلات من قبل (Blanchard, 1990)، إلى أن تم بلورثه وتطبيقه على يد صندوق النقد الدولي في التشعينيات من القرن العشرين، وفقا للشكل

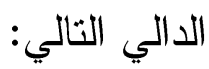

$\bar{d}-d_{t}=\left(r_{t}-n_{t}\right) b_{t}-d_{t}$

ويرتكز مؤشر الفجوة الأولي على فرضية أساسية مفادها أن النسبة المثلى للعجز الأولي إلى الناتج المحلي الإجمالي r المضي قدما على المسار الصحيح للاستدامة المالية هي عبارة عن الفرق بين معدل الفائدة الحقيقي ومعدل النمو الاقتصادي tn مرجحاً بنسبة الدين إلى الناتج المحلي الإجمالي، وبطر ح النسبة الفعلية للعجز أو الفائض الأولي إلى الناتج المحلي الإجمالي d هن طرفي المعادلة؛ يظهر الثكل الدالي السابق للمؤشر، بحيث تعكس القيمة السالبة له زيادة النسبة الفعلية للعجز الأولي عن المستويات المثلى له، بما 
لا يحقق ثبات مستوى نسبة الدين إلى الناتج المحلي الإجمالي ويدفع بالاقتصاد صوب مسار عدم الاستدامة المالية ولقد عانى الاقتصاد المصري من عجز مستمر ومتز ايد في الموازنة العامة للدولة، وذلك نتيجة لزيادة النفقات العامة بمعدل أسرع من الإيرادات العامة وقصور الإيرادات العامة بشكل واضح عن تغطية النفقات العامة، هذا بالإضافة إلى عدم نجاح الحكومة في ترشيد النفقات العامة؛ بسبب التزامها ببعض بنود الإنفاق الاجتماعي الضرورية وعجزها عن تتمية الموارد المالية من خلال زيادة القاعدة الضريبية و القضاء على معدلات التهرب.

وفى ظل اتجاه السلطات الاقتصادية نحو تطبيق برنامج الإصلاح الاقتصادي المصري تبنت الحكومة العديد من الإجر اءات التي تتعلق بإصلاح المالية العامة، وتقوية أدوات السياسة النقدية المتاحة أمام البنك المركزي، ودفع وتيرة الإصداح الهيكلي وتحسين الثفافية في الإطار المؤسسي المتعلق بالتوجه الاقتصادي؛ لذلك كان إصلاح المالية العامة جوهرياً لتحقيق الاسثقرار المالي العام بصفة خاصة، وتصويب السياسات الاقتصادية الكلية وتحقيق الاستقرار الاقتصادي بصفة عامة. وقد مثل عام 1991م البداية الحقيقية للإصلاح المالي، حيث انخفض العجز الكلي للموازنة العامة كنسبة من الناتج المحلي الإجمالي من 17.2\% عام 1991م إلى 5.2\% عام 1992م، وظلت نسبة العجز تأخذ من الاتجاه النزولي سلوكا أساسيا لمسار ها حتى وصلت إلى أدنى قيمة لها خلال فترة الدراسة حين سجلت 0.9 \% بنهاية عام 1997م ، الأمر الذي ساهم في انخفاض النتائج السلبية لمؤشر العجز المالي الأولي دن -25.5 إلى -17.7\% على التو الي، ثم حقق المؤشر نتائج إيجابية بلغت 5.3\% خلال نفس الفترة الزمنية السابقة، ليعكس انخفاض النسبة الفعلية للعجز الأولي عن المستويات المثلى له، بما يحقق ثبات مستوى نسبة الدين إلى الناتج المحلي الإجمالي ويدفع بالاقتصاد المصري صوب مسار الاستدامة المالية، وذلك كما يتضح من الجدول رقم 1 بالملحق الإحصائي. وفي ضوء هذا السيناريو السابق يمكن القول بأن العجز المالي في الموازنة العامة قد وصل إلى مر احل الاستدامة خلال فترة التسعينيات من القرن الماضي. وقد يعزى ذلك إلى العديد من العوامل، ولعل من أهمها الحد من النفقات العامة، كتخفيض بعض بنود الدعم و إلغاء البعض الآخر، وقصر الاستثمارات العامة على المجالات الضرورية، حيث نم ترشيد وتخفيض حجم الإنفاق الحكومي شاملاً الإعانات على 
كثير من السلع و الخدمات بصورة ملحوظة. كما شمل الإصلاح ثرشيد الإنفاق في شركات القطاع العام من خلال التحكم في الإنفاق الإجمالي لهذه الشركات، وتحسين كفاءة إدارة الدين العام لهذه الشركات، بالإضافة إلى تخفيض نكلفة تلك الديون عن طريق إعادة جدولة نواريخ استحقاقها أو استبدالها بديون ذات تكلفة أقل، بالإضافة إلى زيادة الإيرادات العامة كزيادة الرسوم على استهلاك البنزين والتبغ و استحداث الضريبة العامة على المبيعات. وهو ما ساهم في تخفيف الدين العام المحلي داخل الاقتصاد المصري وزيادة الاقتدار المالي العام وتحقيق بيئة اقتصادية مستقرة.13. أضف إلى ما سبق اتجاه الدولة إلى تعديل سياسة التمويل بالعجز، حيث اتجهت إلى الاعتماد على مصادر حقيقية، من خلال الاقتز اض من الأفراد و المؤسسات المصرفية عن طريق أذون الخزانة و السندات الحكومية، بدلاً من الاقتر اض المصرفي الذي يؤدي إلى ارتفاع معدلات التضخم، وهو الأمر الذي ساعد في تحسين البيئة الاقتصادية الكلية. وقد عاود العجز إلى التزايد كقيمة وكنسبة من الناتج المحلي الإجمالي منذ بداية عام 2000م، ويرجع ذلك إلى مجموعة من الأحداث والتغيرات الاقتصادية على الصعد الدولية و الإقليمية و المحلية، بالإضافة إلى مجموعة من الاختلالات الهيكلية من أهمها توجيه موارد الاقتر اض لخدمة أغر اض الإنفاق الجاري وليس الاستثاري، ومن ثم ضعف القدرة على سداد الديون وزيادة حجم الدين العام، بالإضـافة إلى توسع الحكومة في إصدار أذون الخزانة بمعدلات فائدة مرتفعة لتمويل عجز الموازنة وامتصاص السيولة، وكذلك زيادة الاقتر اض التز اكمي للحكومة من بنك الاستثار القومي، حتى وصل إلى 134 مليار جنيه خلا العام المالي 2004/2003م، وبلغت نسبة عجز الموازنة إلى الناتج المحلي الإجمالي 9.5\% خلال نفس العام. وحينما ارتفعت نسبة عجز الموازنة إلى.6\%\% عام 2005م، ارتفعت النتائج السلبية لمؤشر العجز المالي الأولي إلى -4.2\% خلال نفس العام. و اتجه مسار التوازن الاقتصادي المصري صوب تحقيق حالات عدم الاستدامة المالية. وما إن بدأ الاقتصاد المصري في تتفيذ المراحل الأولى من خطط تطوير القطاع المصرفي وتحسين الأداء الاقتصادي حتى بدأت الأزمات تلقى بظلالها على سماء الاقتصاد المصري وتأتي الرياح بما لا تشتهي السفن وتتصاعد حدة التونزات والأزمات الأمنية و السياسية و الاقتصادية و الاجتماعية منذ 25 يناير 2011م مرورا إلى 30 يونيو 2013م وما بعدها , وهو الأمر الذي ساهم في زيادة حالات عدم الاستقر ار الأمني و انعكاساتها السلبية على حركة السياحة و التجارة و النقل و الاستثمار ، و انخفاض معدلات 
التشغيل والإنتاج ومعدلات النمو الاقتصادي؛ مما أدى إلى زيادة نسبة عجز الموازنة إلى الناتج المحلي الإجمالي لتسجل 13.7\% عام 2013م، ولقد ساهم هذا الأمر في وصول الاقتصاد المصري لمر احل عدم الاستدامة المالية حين كسرت نسبة العجز في مؤشر العجز المالي الأولي لحاجز الــ 7\%، وارتفعت هذه النسبة إلى -7.9\% خلال نفس العام.

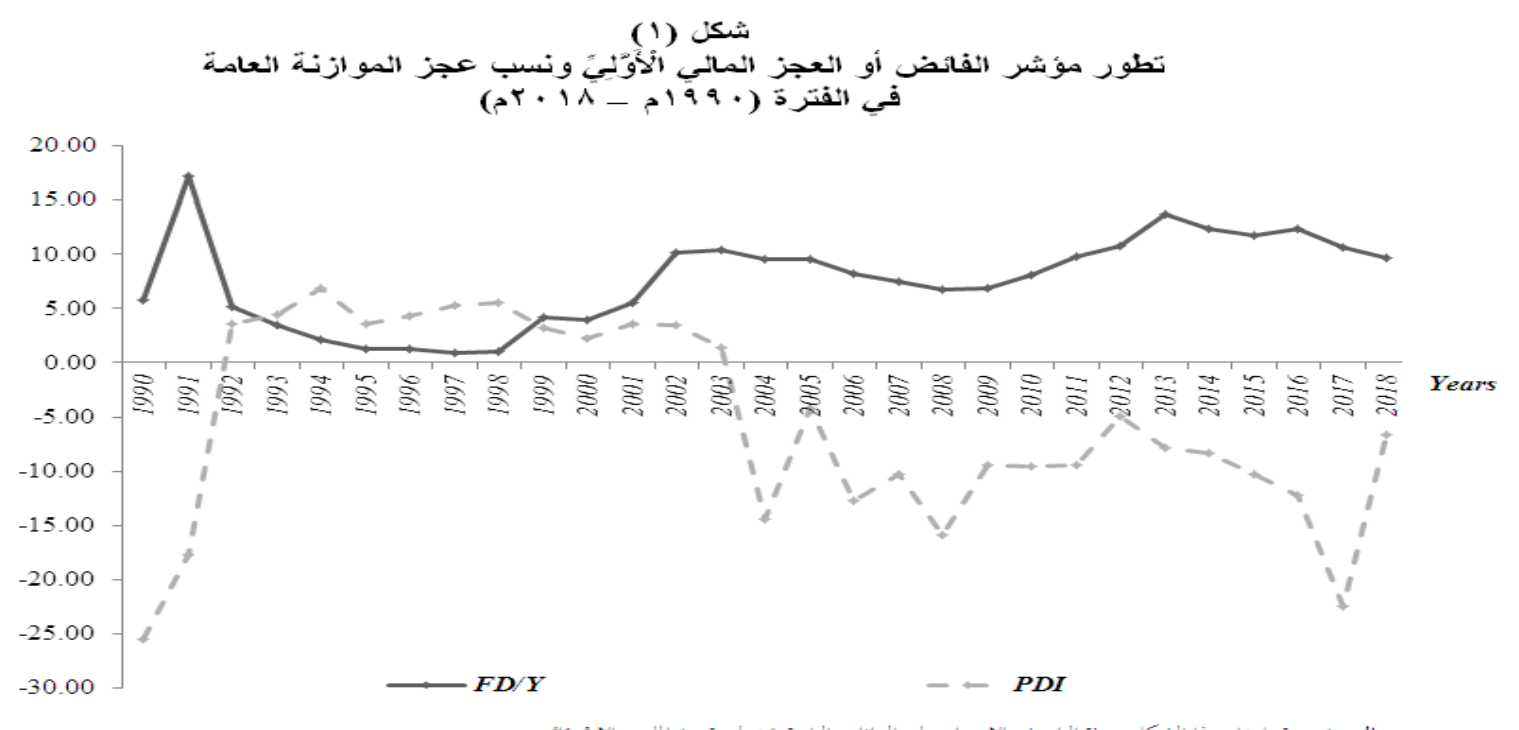

وبحلول عام 2016 م بات و اضحا عدم التتاسق بين الطريقة التي يتم بها وضع السياسات الاقتصادية الكلية المطبقة داخل الاقتصاد المصري مع طريقة إدارة معدل الصرف، الأمر الذي نجمت عنه بيئة اقتصادية غير مستقرة؛ ازدادت بداخلها الثقلبات في معدل الصرف الحقيقي في ظل نظم معدلات الصرف المختلفة المطبقة داخل الاقتصاد المصري. كما انخفضت فعالية السياسة النقدية وارتفعت مسنويات العجز المالي؛ مما أدى إلى زيادة تكلفة المعاملات وضعف القدرة التتافسية للصناعات الوطنية، الأمر الذي انعكس في شكل استنز اف لمستوى صافي الاحتياطيات الدولية المحتفظ به من قبل السلطات النقدية، و انخفاض دعدلات النمو الاقتصادي والاستثمار و التوظف والناتج، وارتفاع معدلات التضخم وتر اكم مستويات الدين المحلي الإجمالي إلى نسب يصعب على الاقتصاد المصري الاستمر ار في تحملها، ولقد كان نتاجاً منطقياً لذلك أن يو افق المجلس التتفيذي لصندوق النقد الدولي في نوفمبر 2016 م على تقديم مساعدة مالية لمصر من خلال اتفاق للاستفادة من "تسهيل الصندوق الممدد" EFF بقيمة 8.59 مليار وحدة حقوق سحب خاصة، أي حوالي 12 مليار دولار أمريكي؛ ليجد الاقتصاد المصري نفسه أمام سيناريو لم يتحقق منذ 16 عاما وهو تحقيق فائضا أوليا في الموازنة العامة للاولة يصل إلى 4.66 مليار 
جنيه بنسبة 0.1 \%، وذللك عندما انخفض العجز الكلي للمو ازنة العامة كنسبة من الناتج المحلي الإجمالي من 12.3\% عام 2016م إلى 9.7\% عام 2018م • وقد أدى ذلك الأمر في انخفاض النتائج السلبية لمؤشر العز المالي الأولي من -12.2\% إلى -6.6\% على التوالي، ليدفع بالاقتصاد المصري صوب مسار قابلية عدم الاستدامة المالية للانعكاس، وذلك كما يتضح من الثكل رقم (1).

2/4 مؤشر الفجوة الضريبية

برى أنصار المناهج اليقينية لقياس مسار الاستدامة المالية أن تضييق الفجوة بين الإيرادات السيادية المتوقع تحصيلها والإيرادات الفعلية المحصلة؛ ستدفع بالدين المحلي الإجمالي في الفترات الزمنية Tax Gap المستقلية إلى وضع مستقر. ولقد اتجه أنصار هذه المناهج لبناء مؤشر الفجوة الضريبية Indicator الاجنماعية والتحويلات الملزمة، وارتكازا على استبعاد الإيرادات غير السيادية للتعرف على مدى مساهمة الإيرادات السبادية في تعزيز مستويات الاقتدار المالي أو كبح جماح الدين المحلي الإجمالي. ويرتكز مؤشر الفجوة الضريبية على فرضية أساسية مفادها أن النسبة المنلى لنسبة الضر ائب إلى الناتج المحلي الإجمالي $\bar{t}$ اللازمة لتتبيت نسبة الدين إلى الناتج المحلي الإجمالي r المضي قدماً على المسار الصحيح للاستدامة المالية هي عبارة عن الفرق بين معدل الفائدة الحقيقي

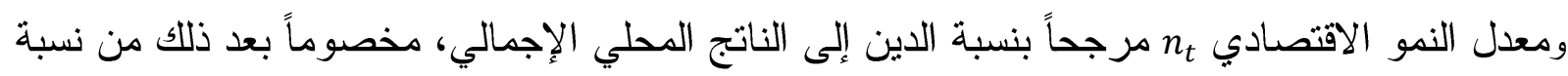
الإنفاق العام ، بدون مدفوعات الفو ائد، إلى الناتج المحلي الإجمالي tg، وبطرح هذه النسبة من النسبة الفعلية للإير ادات السيادية إلى الناتج المحلي الإجمالي t في طرفي المعادلة ـ ويظهر الثكل الدالي التالي للمؤشر، بحيث تعكس القيمة السالبة له عجز نسبة الضرائب الفعلية عن ملاحقة نسبة الضرائب المنلى، بما لا يحقق ثبات مستوى نسبة الدين إلى الناتج المحلي الإجمالي ويدفع بالاقتصاد صوب مسار عدم الاستدامة المالية $t_{t}-\bar{t}=t_{t}+\left(r_{t}-n_{t}\right) b_{t}-g_{t}$

ولقد أكد (Blanchard, 1990) أن نسبة الضر ائب إلى الناتج المحلي الإجمالي الفعلية يجب أن تغطي جز ءا من تبار الإنفاق العام الأولي ومدفو عات خدمة الدين المحلي الإجمالي غير المغطى من قبل حصيلة

${ }^{14}$ The Policy Development and Review Department, "Assessing Sustainability", Op. cit., PP 7 - 8. 
النمو في الناتج المحلي الإجمالي الحقيقي، ومن ثم فإن النتائج السلبية لهذا المؤشر في الآجال القصيرة و المتوسطة قد لا تتطلب إحداث تغيرات جذرية في هيكل السياسات المالية الديناميكية المطبقة داخل الاقتصاد المعني، إذا كان هناك قابلية لعدم الاستدامة المالية للانعكاس. و إذا أسفرت نتائج هذه الفجوة عن مؤشرات سالبة في الأجل الطويل فإن ذلك ينطلب إحداث تغيرات جذرية في هيكل السياسات المالية الديناميكية المطبقة داخل الاقتصاد المعني، دون الحاجة إلى النظر لدو ال رد فعل هذه السياسات وقابليتها للانعكاس في الآجال الزمنية الأخرى 15. ويتضح من الثكل رقم 2 وجود ثمة علاقة ارتباط شبه تام بين نتائج مؤشري الفائض أو العجز المالي الأولي و الفجوة الضريبية داخل الاقتصاد المصري خلال فترة الدراسة، ففي ضوء السيناريو السابق، الذي من خلاله نم التوصل إلى أن العجز المالي في الموازنة العامة للاقتصاد المصري قد وصل إلى لى مر احل الاستدامة خلال فترة التسعينيات من القرن الماضي، وفقا لمؤشر الفائض أو العجز المالي الأولي؛ أظهر مؤشر الفجوة الضريبية تأكيدا على هذه النتائج عندما سجلت القيم البينية المحسوبة له مسار ا تتازليا من -26.2\% عام 1992م إلى -66\% عام 2003م، قبل أن بنطلق قطار مر احل عدم الاستدامة المالية للاقتصاد المصري عندما سجلت القيم البينية المحسوبة لمؤشر الفجوة الضريبية مسار ا تصاعديا من -18.6\% عام 2004م إلى -30.5\% عام 2017م؛ ليقف مرة أخرى صوب مسار قابلية عدم الاستدامة المالية للانعكاس، بتحقيق فائضا أوليا في الموازنة العامة للاولة بنسبة0.1 \% \% و وانخفاض النتائج السلبية لمؤشر الفجوة الضريبية ليسجل -13\% خلال عام 2018م.

\footnotetext{
${ }^{15}$ Blanchard, O., et.al., "The Sustainability Of Fiscal Policy: New Answers To An Old Question", OECD Economic Studies, Working paper No.15, 1990, PP 12 - 18.
} 


\section{شكل رقم (2)}

العلاقة بين مؤشري الفائض أو العجز المالي الأولي والفجوة الضريبية داخل الاقتصاد المصري

$$
\text { في الفترة (1990م - 2018م) }
$$

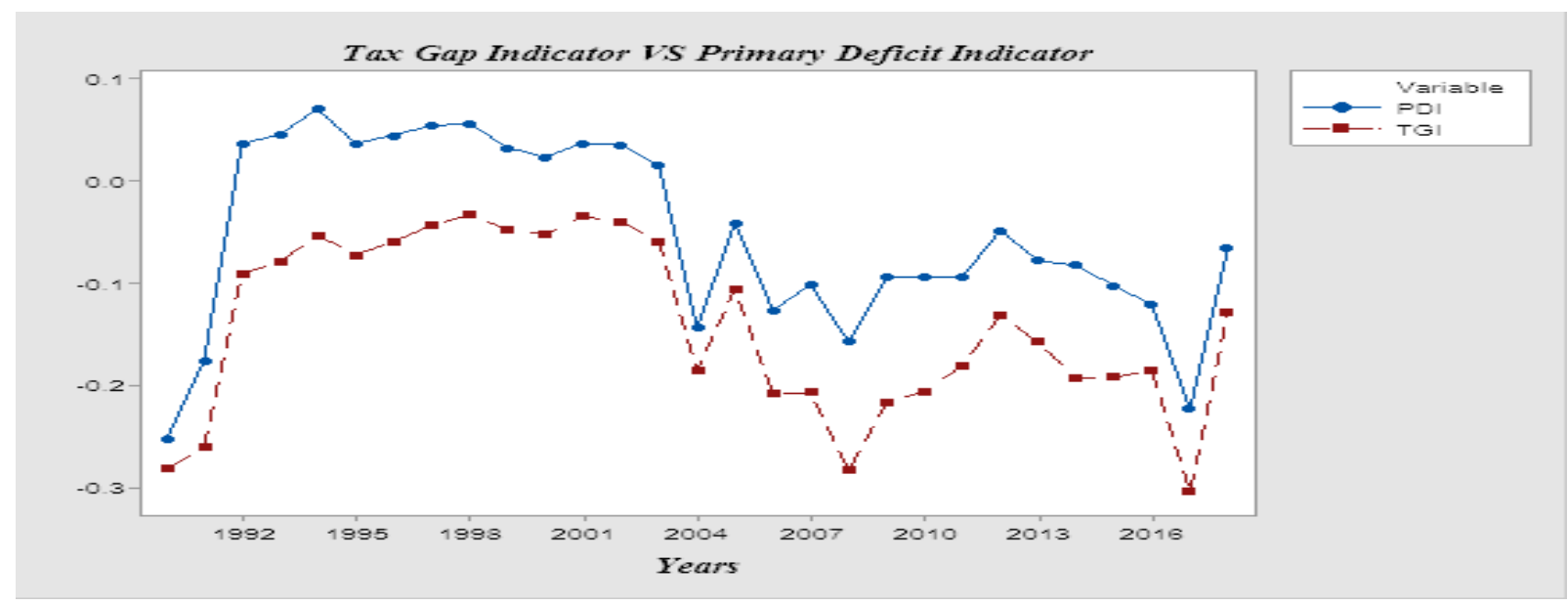

المصدر : تم إعداد هذا الشكل بمعرفة الباحث بالاعتماد على البيانات الواردة بجدول رقم 1 بالملحق الإحصائي.

و إن تم قبول النتيجة الأولية فقط لهذا السيناريو السابق "بأن الاقتصاد المصري قد شهد حالات عدم الاستدامة المالية القابلة للانعكاس على مدار فترة الدراسة" فإن التغيرات الجذرية و الهيكلية في نظم معدلات الصرف الفعلية المطبقة، والتغيرات الأخرى المناظرة في السياسات الاقتصادية الكلية المطبقة داخل الاقتصاد المصري منذ عام 2016م؛ وحدها كفيلة بقبول الفرضية الأساسية لهذه الدراسة والتي مفادها "أن الاقتصاد المصري قد شهد حالات عدم الاستدامة المالية على مدار فترة الدر اسة، إلا أنها قد تكون قابلة للانعكاس في الأجل المتوسط".

5- نماذج التوازن العام العشوائية الديناميكية لقياس مسار الاستدامة المالية داخل الاقتصاد المصري حاول العلماء منذ عام 1943م التوصل إلى نظام قادر على التفكير و التعلم، يمكن من خلاله محاكاة القدرات الطبيعية للعقل البشري ويساهم في حل المشاكل التطبيقية المعقدة، والتي لا نستطيع الحاسبات التقليدية حلها. ولقد أسفرت هذه المحاو لات عن ظهور نماذج الثبكات العصبية التي تعد بمثابة نوع جديد من أنواع الذكاء الاصطناعي يحاكي الخصائص الرئيسة و اللازمة لنجاح آليات العمل الطبيعية للخلايا العصبية المكونة للعقل البشري. و على إثر ذلك قام (Rotemberg and Woodford, 1977) بنطوير أساليب البرمجة الديناميكية الحسابية Numerical Dynamic Programming Methods لوضع اللبنة الأولى لنماذج التو ازن العام العشو ائية الديناميكية DSGE Models، و التي تعد تطور اً طبيعياً لنماذج 
الدورات الاقتصادية الحققية RBC Models. حيث قامت هذه النماذج بحسم الجدل الدائر بين رواد الددرسة الكينزية الحديثة ورواد الددرسة الكلاسيكية الحديثة في التسعينيات من القرن العشرين، من خلال جمعها بين قدرة النماذج الكلاسيكية الحديثة على توضيح عملية اتخاذ القرارات من قبل الأفر اد و المنتجين عبر الزمن، وبين فروض النماذج الكينزية الحديثة المتعلقة بالجمود في الأسعار والأجور، وسيطرة المنافسة الاحتكارية على هيكل الأسواق، و إلغاء فرضية انعدام فعالية السياسة النقدية في التأثير على الثق الحقيقي للاقتصاد.

ويتضمن مصطلح نماذج النو ازن العام العشو ائية الديناميكية ثلاث معان داخلية: - - اصطلاح الديناميكية، الذي يشير إلى توصيف دو افع وسلوك وقرارات الفاعليين الاقتصاديين عبر الزمن من خلال التوقعات الحالية للمسار و السلوك المستقبلي للمتغيرات الاقتصادية الكلية، - اصطلاح الثوازن العام، ويعبر عنه النماذج من خلال التفاعل بين السياسات الاقتصادية الكلية وسلوك الفاعليين الاقتصاديين، كما تقدم هذه النماذج نوصيفا مفصلا للقنوات والآليات التي تنتقل من خلالها الصدمات الحقيقية العشو ائية داخل الجسد الاقتصادي. - - اصطلاح العشوائية، ويتتبع تقييم آثار التفاعلات على المتغيرات الاقتصادية الكلية. وتتميز نماذج التو ازن العام العشو ائية الديناميكية بالعديد من المز ايا التي تجعل منها الملاذ الآمن والأكثر جاذبية عند رسم وتصميم وتحليل أداء السياسات الاقتصادية الكلية، ومن هذه المز ايا: الهيكلية بمعنى أن كل معادلة سلوكية لها تفسير ومدلول اقتصادي يساعد على تحديد التفاعلات بين السياسات الاقتصادية الكلية وتحليل وتتبع قنو ات انتقالها و التعرف بوضوح على السياسات البديلة، تم تأسيس هذه النماذج على أسس متتاهية الصغر مستوحاة من أسس ومبادئ الاقتصاد الجزئي في توصيفها لدو افع وسلوك القطاع العائلي وقطاع الأعمال و القطاع الحكومي و البنوك المركزية وتتبع سعيهم لتعظيم منافعهم و عدم تغيير هم لقر ار ات الأمثلية في ظل تغير الوضع الحالي للسياسات الاقتصادية الكلية، كما تسنطيع هذه النماذج تقييم وتحليل الآثار الاقتصادية الكلية لانتقال الصدمات الحقيقية العشو ائية داخل مسارات القنوات الاقتصادية

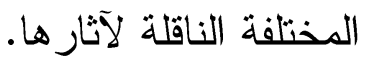
ولقد استطاع كل من (Lawrence, C., et.al., 2001) إدخال بعض المعلمات على هذه النماذج لعل من أهمها: سيطرة العادة على تفضيلات المستهلكين، وتكلفة مو ائمة الاستثمار ، و التغيرات في معدلات استغلال رأس المال، بالإضافة إلى القدرة على تحديد السياسات المناسبة جر اء تعرض الاقتصاد لصدمات المساعدات و الصدمات التكنولوجية؛ مما ساهم في تفسير الاستخدام الموسع لنماذج التوازن العام العشو ائية 
الديناميكية من قبل السلطات النقدية على مستوى العالم و الاعتماد عليها بشكل كبير في رسم وتصميم وتتفيذ السياسات الاقتصادية الكلية والتتبؤ بالأداء الاقتصادي وتحليل التفاعلات و السلوك العشوائي للمتغير ات الاقتصادية الكلية في مر احل الدورات الاقتصادية.16.

وقد بدأ التوصيف الهيكلي الرئيس لهذا النموذج بافتر اض وجود ثلاث وحدات متداخلة Three : فينا Interrelated Blocks

$$
\text { - - ت أما الثانية فنتصدى لأولى بجانب الطلب في الاقتصاد، }
$$

- متختص الوحدة الثالثة بجانب السياسة النقدية.

وتستمد كل وحدة الثكل الدالي لها من أسس وفروض نظرية الاقتصاد الجزئي لسلوك القطاع العائلي وقطاع الأعمال و القطاع الحكومي؛ شريطة أن يكون التذاخل و التفاعل بين هؤلاء الفاعلين الاقتصاديين يتحدد داخل أسو اق تتوازن آنياً وبصفة متكررة؛ مما يساعد في دفع مسار ات المتغير ات الاقتصادية الكلية نحو حالة التوازن العام في نماذج التوازن الاقتصادي الكلي. ولم تستمر هذه الفترة التي عاشتها نماذج التوازن العام العثوائية الديناميكية تحت مظلة هذه الوحدات الثلاثة طويلا، إلى أن أصيبت هذه النماذج بعنصر الجمود في وحداتها ، فما إن اندلعت الأزمة الاقتصادية العالمية بحلول النصف الثاني من عام 2007م، إلا وجاءت تحمل في ثناياها الانفتاح الكامل من جانب نماذج التوازن العام العشو ائية الديناميكية للباحثثن لإضافة عدد الوحدات التي يستهدفونها والصدمات التي يتعرض لها الاقتصاد المعني مثل الاحتكاكات في عملية التر اكم الر أسمالي و الوساطة المالية كأحد القنو ات الرئيسة التي تتنقل بها الصدمات إلى الجسد الاقتصادي؛ لتجعل نماذج التوازن العام العشو ائية الديناميكية من نفسها نماذج تفصيلية من قبل صانعي السياسات الاقتصادية و الباحثين بما يتلائم مع الاقتصاد المعني. ويمكن تقدير نماذج التوازن العام العثوائية الديناميكية من خلال خمس وحدات ومراحل تبدأ أولها بتوصيف المتغير ات المحددة Predetermined variables و الخارجية و الداخلية للنموذج من خلا الأمر; ... var $X_{1}: \ldots, X_{n}$, and varexo أما الوحدة الثانية فتختص بتوصيف المعلمات

\footnotetext{
${ }^{16}$ Slanicay, M., "Some Notes on Historical, Theoretical, and Empirical Background of DSGE Models",
} Review Of Economic Perspectives, Vol.14, No.2, 2014, PP 145 - 164. 
Parameters بالأهر ; parameters cbeta, eta, sig, ... , crho,... وتتصدى الوحدة الثالثة لتوصيف النموذج وتحديد القيم الأولية لمتغيرات النموذج من خلال الأمر ( ثم المعايرة الأولية لمتغيرات النموذج من خلال الأمر ; initval; ............ end ، على الجانب الأخر تدخل مرحلة تحديد الصدمات العشوائية التي يتعرض لها الاقتصاد المعني ضمن الوحدة الرابعة لهذا النموذج والتي يمكن كتابتها بالأمر; shocks; ..........Shocks Description .......... end ثم يتم تقدير هذا النموذج عند مرحلة استقرار الأوضاع Steady State، و افتر اض حالة الأمثلية داخل الاقتصاد المعني من خلال . stoch_simul( (............); الأمر وتأتي المرحلة الخامسة والأخيرة لتصدى لتقدير النموذج و المعلمات المقدرة بداخله وذلك من خلا .varobs $X_{1} ;$ estimated _params; ...........end; estimation (......); الأمر و أخيراً وليس أخراً يتجه بعض الاقتصاديين إلى تقدير نماذج التوازن العام العشوائية الديناميكية من خلال ست وحدات، وذلك بإضافة وحدة أخيرة إلى الوحدات سالفة الذكر وهي مرحلة التتبؤ المشروطة

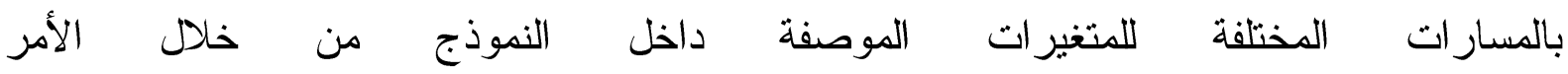
. ${ }^{*}$ conditional_forecast_paths; ..........., conditional_forecast $(. . . .$.$) ;$ تعد مناهج المعايرة Calibration وطرق العزوم المعدة Generalized Method Of Moments ودوال الاستجابة للصدمات Impulse Response Function ومناهج نسبة الإمكانيات العظمى Maximum likelihood Test DSGE إلا أن ثورة الاقتصاد القياسي البيزي Bayesian Econometrics - والتي ظهرث في منتصف السبعينيات من القرن العشرين - جاءت لتحمل في ثناياها المنهج القياسي الأدق و الأنسب لتقدير نماذج التوازن العام العشوائية الديناميكية ـ وذلك من خلال التوسع الهائل في استخدام سلسلة ماركوف مونت كارلو Markov Chain Monte Carlo Methods والتي تحتوي على مجموعة من التقنيات و الخوارزميات الحسابية التي تسعى إلى محاكاة التوزيعات الاحتمالية البعدية المختلفة التي تتنمي إليها

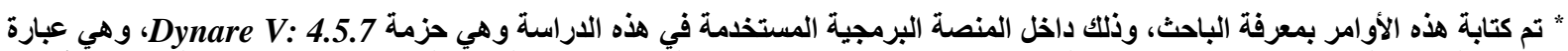

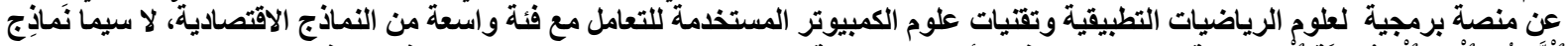

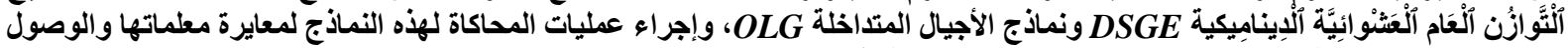

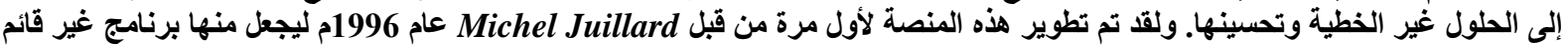

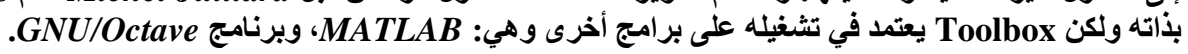


معلمات النموذج. وتبدأ عملية الاستدلال البيزي عن معلمات النموذج من خلال إيجاد التوزيع الاحتمالي البعدي Posterior

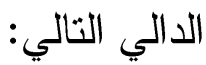

$\pi\left(\theta \mid y^{T}\right)=\frac{p\left(y^{T} \mid \theta\right) \pi(\theta)}{\int p\left(y^{T} \mid \theta\right) \pi(\theta) d \theta}$,

على الجانب الأخر ينت حساب التوزيع الاحتمالي القبلي Prior الإمكانيات العظمى وذلك من خلال الثكل الدالي التالي:

$\left(y^{T} \mid \theta\right)=p\left(y_{1} \mid \theta\right) \prod_{t=2}^{T} p\left(y_{1} \mid y^{t-1} ; \theta\right)$

$=\int p\left(y_{1} \mid s_{1} ; \theta\right) d S_{1} \prod_{t=2}^{T} \int p\left(y_{1} \mid s_{t} ; \theta\right) p\left(s_{t} \mid y^{t-1} ; \theta\right) d S_{t}$

على الجانب الأخر يتم حساب التوزيع الاحتمالي البعدي لمتغيرات الحالة في الفترة الزمنية الحالية p $p\left(S_{t} \mid y^{t} ; \theta\right)$ المشاهدة في القترة الأولى Chapman-Kolmogorov Equation التي تأخذ الثكل الدالي التالي: $p\left(s_{t+1} \mid y^{t} ; \theta\right) d S_{1} \int p\left(s_{t+1} \mid s_{t} ; \theta\right) p\left(s_{t} \mid y^{t} ; \theta\right) d S_{t}$

$p\left(S_{t} \mid y^{t} ; \theta\right)=\frac{p\left(y_{t} \mid S_{t} ; \theta\right) p\left(S_{t} \mid y^{t-1} ; \theta\right)}{p\left(y_{t} \mid y^{t-1} ; \theta\right)}$,

$p\left(y_{1} \mid y^{t-1} ; \theta\right)=\int p\left(y_{t} \mid S_{t} ; \theta\right) p\left(S_{t} \mid y^{t-1} ; \theta\right) d S_{t}$,

و على إثر ذلك يتم اللجوء إلى أسلوب تتقية كالمان kalman filter لحساب معادلات التحول من متجه متغير ات الحالة S إلى معادلات القياس لمتجه المتغير ات المشاهدة y و والتي تأخذ الثكل الخطي لنموذج الانحدار البسيط؛ شريطة الوصول إلى متجه أخطاء 
صافية Pure Random Process أو عملية تشويش بيضاء White Noise Process، وذلك من خلا

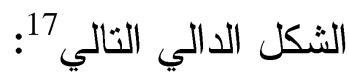

$S_{t}=A s_{t-1}+B \varepsilon_{t}$

$y_{t}=C s_{t}+D \varepsilon_{t}$

$\varepsilon_{t} N(0,1)$,

6- توصيف نماذج التوازن العام العشو ائية الديناميكية و المعادلات السلوكية لقياس مسار الاستدامة المالية داخل الاقتصاد المصري استخدم كل من (Mendoza ,and Oviedo, 2004) النهج النيوكلاسيكي للوصول إلى نماذج نوازن عام عشوائية ديناميكية تلائم اقتصاديات الدول النامية، و التي تتسم بصغر حجما وتأثزها بالصدمات الخارجية و العشو ائية؛ الأمر الذي يجعل إير اداتها العامة تتحدد بشكل خارجي، ويجعل من نفقاتها العامة متغير تابع لحجم إير اداتها. كما تم اقتر اح وضع حدود للدين طبيعية NDL تتعهد الحكومات بدفعها وعدم الاقتر اض بأعلى من هذه الحدود. وفي سياق هذا النموذج التي اتخذته العديد من الدراسات التطبيقية

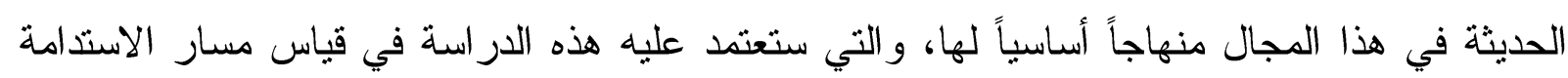
المالية داخل الاقتصاد المصري. وقد افترض النموذج أن القطاع العائلي يحاول تعظيم منفعته من خلال هله دخله Yt الذي يزيد بزيادة التحويلات و المنح و الإعانات الحكومية وينخفض بزيادة الضرائب $\tau$ التي

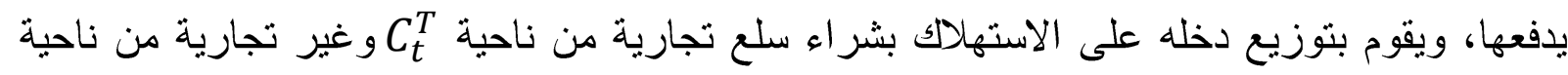
أخرى

$\underset{\left\{C_{t}^{T}, C_{t}^{N}, b_{t+1}\right\}^{\infty}}{\max } E\left[\sum_{t=0}^{\infty} \exp \left\{-\sum_{T=0}^{t-1} \beta \ln \left(1+c_{T}+g_{T}\right)\right\}\left(\frac{c_{t}^{1-\sigma}}{1-\sigma}+\frac{g_{t}^{1-\sigma^{g}}}{1-\sigma^{g}}\right)\right]$

17 Villaverde, J., "The econometrics of DSGE models", Journal of the Spanish Economic Association, Vol.10, No.4, 2010, PP 7 - 17. 
يسعى القطاع العائلي في ضوء دالة الهدف السابقة إلى تعظيم منفعته بمعامل مرونة التفضيلات الزمنية

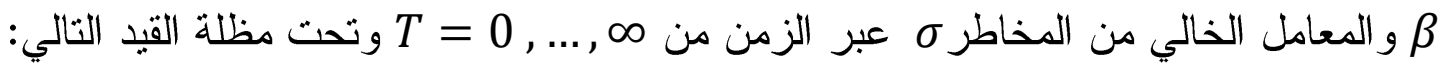

$C_{t}^{T}+p_{t}^{N} C_{t}^{N}+\gamma b_{t+1} \leq(1-\tau)\left(Y_{t}^{T}+p_{t}^{N} Y_{t}^{N}\right)+R b_{t}+p_{t}^{N} \omega$

افترض النموذج أن القطاع الحكومي - أيضا - يحاول تعظيم منفعة الأفر اد من خلال سياسة الإنفاق العام $g_{T}$ و الدين العام المحلي الإجمالي كنسبة من الناتج المحلي الإجمالي tb في إطار دالة الهدف التالية:

$\max _{\left\{g_{t}^{T}, g_{t}^{N}, b_{t+1}\right\}_{t=0}^{\infty}} E\left[\sum_{t=0}^{\infty} \exp \left\{-\sum_{T=0}^{t-1} \beta \ln \left(1+c_{T}+g_{T}\right)\right\}\left(\frac{g_{t}^{1-\sigma^{g}}}{1-\sigma^{g}}\right)\right]$,

يسعى القطاع الحكومي في ضوء دالة الهدف السابقة إلى تعظيم منفعته تحت مظلة القيد التالي الذي يوضح أن نسبة الدين مرجحة بمعامل التفضيلات الحكومية في الفترة القادمة $\gamma b_{t+1}$ ما هي إلا عبارة عن الفرف بين الإيرادات الحكومية من قطاعي السلع التجارية وغير التجارية ومدفو عات خدمة الدين Rb من أجل زيادة الرفاهه(

$\gamma b_{t+1} \leq R b_{t}+g_{t}^{T}+P_{t}^{N}\left(g_{t}^{N}+\omega\right)-\tau\left(y_{t}^{T}+P_{t}^{N} y_{t}^{N}\right)$

وبإخخال مضاعف لاجر انج $\lambda$ وحل هذه النماذج بأخذ المشنقات الجزئية عند حالة التوازن الآني للسوق وحالة اسثقر ار الأوضاع؛ تم الثوصل إلى الثكل النهائي الذي يوضح المعادلات السلوكية السبع لنماذج التوازن العام العشو ائية الديناميكية داخل الاقتصاد المصري لقياس مسار الاستدامة المالية على النحو التالي 18:

${ }^{18}$ Mendoza, E., and Oviedo, P., " Fiscal Solvency and Macroeconomic Uncertainty in Emerging Markets: The Tale of the Tormented Insurer", The Research Department of The Inter-American Development Banks - IADB, Working paper No.153, 2004, PP 1 - 72. 
$\frac{1-\delta}{\delta}\left(c_{t}+g_{t}\right)^{1-\eta}=P_{t}+b_{t}$

(38); $\quad \frac{\gamma}{1-b_{t}}=\frac{g_{t}}{y_{t}}$

$g_{t}^{1-\sigma}=\left(1+c_{t}+g_{t}\right)^{\beta}\left\{b_{t}\right\}^{1-\sigma},(40) ; y_{t}=-r b_{t}+\gamma b_{t+1}+c_{t}+g_{t}$,

$b_{t}=e^{z}\left\{\frac{g_{t}}{y_{t}}\right\}, \quad(42) ; \quad r b_{t}=e^{z}\left\{\frac{b_{t}}{g_{t}}\right\},(43) ; \quad z_{t}=\rho z_{t-1}+\varepsilon_{t}$,

وتوضح المعادلات السلوكية لنماذج التوازن العام العشوائية الديناميكية أن الاستدامة المالية داخل الاقتصاد المصري تعني تحقق إدارة الدين المثلى والني تتحقق عند حدوث الثوازن في سلوك الأفراد وسلوك الحكومة أو عندما تتساوى النكلفة الحدية للدين المصدر مع العائد المتحقق منه، فالقطاع العائلي عند شر ائهم للسندات الحكومية يقوموا بالمفاضلة بين المنفعة الحدية التي يحصلوا عليها منه و التكلفة الحدية التي يتحملوها، وكذلك القطاع الحكومي عند إصدار هذه السندات تفاضل بين التكلفة الحدية التي بني تتحملها عند إصدار السندات $\sigma$ مع العائد الحدي المتحقق من هذا الإصدار $\delta$ ـ في حين تختص المعادلة رقم 44 بإيضاح أن الصدمات العشو ائيةtz التي يتعرض لها الاقتصاد المصري تتحدد وفقا لدالة الارتباط

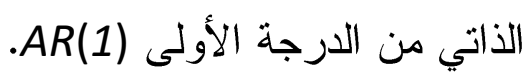
ولقد تم حصر المتغير ات الاقتصادية المشاهدة و المكونة للمعادلات السلوكية لنماذج التو ازن العام العشو ائية الديناميكية داخل الاقتصاد المصري وذلك باستخدام بيانات سلسلة زمنية تغطى الفترة من عام 1990م إلى عام 2018م، وسيتم التعبير عن هذه المتغيرات و إدخالها في طبقات لنماذج النوازن العام العشو ائية

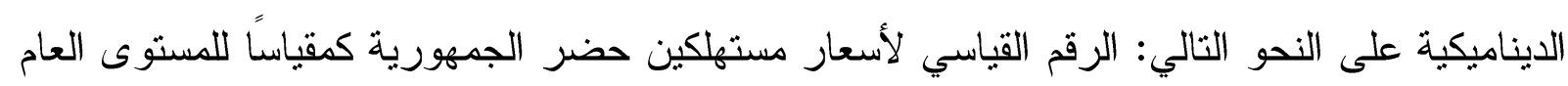
للأسعار P وذلك باعتبار عام 1990م هو سنة الأساس - الناتج المحلي الإجمالي الحقيقي بتكلفة عوامل الإنتاج و الأسعار الثابتة لعام 1990 y - y و الدين العام المحلي الإجمالي كنسبة من الناتج المحلي الإجمالي - - ومدفو عات خدمة الدين العام المحلي الإجمالي rb - وحجم الإنفاق الاستهلاكي العام g و بالإضافة إلى متغير الصدمات العشوائية التو ازن العام العشو ائية الديناميكية وهو تساوي عدد المتغير ات السابقة مع عدد المعادلات السلوكية السبع

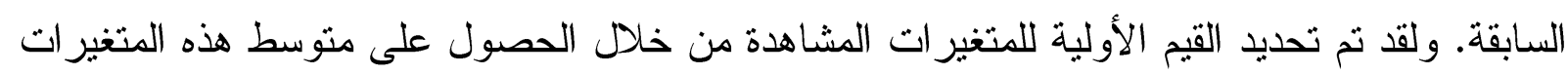


وتعد مناهج المعايرة الأولية لمعلمات النموذج هي الخطوة التالية بعد توصيف المتغيرات وتحديد القيم الأولية لها، فلقد تم معايرة معلمة مرونة التفضيلات الزمنية م بالقيمة الأولية لها 0.99 ومعلمة العائد الحدي المتحقق من الديون $\delta$ فلها توزيع احتمالي قبلي بقيمة 0.36 على أن يتبعها توزيع احتمالي بعدي بقيمة 0.09 عند الثقدير، ولقد ثم معايرة معلمة المعامل الخالي من المخاطر م ومرونة الإحلال النقدي $\eta$ بتوزيع احتمالي قبلي بالقيم 0.67، 0.05 على التوالي، على أن يتبعا توزيع احتمالي بعدي inv_gamma_pdf بقيمة 0.9 عند التقدير، أما معلمة معدل نمو الدين العام في الأجل الطويل فلها توزيع احتمالي قبلي بقيمة واحد صحيح على أن تتبع توزيع احتمالي بعدي normal_pdf بقيمة 0.5 عند التقدير ، وأخير ا تم معايرة معلمة معامل الانحدار الذاتي من الارجة الأولى م بالقيمة الأولية لها 0.5 على أن تتبع توزيع احتمالي بعدي uniform_pdf بقيمة 0.2887. 7-تقدير نماذج التوازن العام العشوائية الديناميكية داخل الاقتصاد المصري بعد الانتهاء من المرحلة الأولى، وهي صياغة الخو ارزم المقترح لتدريب نماذج التوازن العام العشو ائية الديناميكية تأتي الخطوة الثانية، وهي التدريب الأولي لهذه النماذج بإدخال الصدمات العشو ائية ومعايرة معلمات النموذج وتحديد القيم الأولية للمتغيرات عند حالة استقرار الأوضاع Initial Steady State؛ من أجل الوصول إلى الأوزان المتلى و المخرجات المستهدفة لبحث مدى ملائمة النموذج لاختبار مسار الاستدامة المالية داخل الاقتصاد المصري؛ وذلك وفقا لما هو موضح بالملحق الفني رقم (1) للأوامر البرمجية ونتائج تقدير نماذج التوازن العام العشوائية الديناميكية داخل الاقتصاد المصري عند حالة استقر ار الأوضاع، ولقد جاءت النتائج على النحو التالي: إن حدوث صدمة عشو ائية إيجابية واحدة مقدرة بانحر اف معياري 1\% تؤدي إلى ارتفاع الدين العام المحلي الإجمالي كنسبة من الناتج المحلي الإجمالي بمقدار 6\%، ثم تتخذ هذه النسبة مسار ا عكسيا قابلا للانعكاس، إلى أن يتلاشى أثر هذه الصدمة بحلول الفترة الزمنية رقم 7. وجود علاقة طردية معنوية بين الدين العام المحلي الإجمالي كنسبة من الناتج المحلي الإجمالي في الفترة الحالية كمتغير داخلي والدين العام المحلي الإجمالي كنسبة من الناتج المحلي الإجمالي في بفترة إبطاء واحدة كمتغير تفسيري، فالزيادة في هذا الأخير بنسبة 1\% تؤدى إلى زيادة الدين العام

${ }^{19}$ Griffoli, T., "Dynare V4 - User Guide (Public Beta Version", January 2013, PP 1 - 45. 
المحلي الإجمالي كنسبة من الناتج المحلي الإجمالي في الفترة الحالية بمقدار 0.54 \%؛ إلا أن معامل الانحدار الذاتي ينخفض عبر الزمن ليصل تأثيره إلى 0.04\% عند فترة الإبطاء رقم 5. الزيادة في مقدار الصدمات العشو ائية داخل الاقتصاد بنسبة 1\% تؤدي إلى زيادة مماثلة في مدفو عات خدمة الدين العام المحلي الإجمالي rb بمقدار 0.55\% تفوق مثيلتها في التأثير على الدين العام المحلي الإجمالي كنسبة من الناتج المحلي الإجمالي بمقدار 0.12\%، وقد يرجع ذلك إلى زيادة تكلفة خدمة الديون في هذه الفترات، وهي نفس الحالة الني شهدها الاقتصاد المصري حيث ارتفعت مدفوعات خدمة الدين بنسبة 36\% منذ عام 2017م إلى عام 2018م، مقابل نسبة 17\% ارتفاع للاين العام المحلي الإجمالي كنسبة من الناتج المحلي الإجمالي خلال نفس الفترة، بما يجعل النموذج أكثر ملائمة لحالة الاقتصاد المصري. وجود ارتباط طردي قوي بين الدين العام المحلي الإجمالي كنسبة من الناتج المحلي الإجمالي ومدفو عات خدمة الدين العام المحلي الإجمالي بمعامل ارتباط 0.99، ومن هذه النتائج الو اردة أعلاه، يمكن القول بأن توصيف نماذج التو ازن العام العشو ائية الديناميكية على النحو السابق تصلح لاختبار مسار الاستدامة المالية داخل الاقتصاد المصري،

ومن ثم يمكن الدخول في مرحلة الثقدير النهائي بشرط إدخال البيانات الخاصة بالمتغيرات المشاهدة؛ وبالنظر إلى نتائج تدريب وتقدير نماذج التوازن العام العشوائية الديناميكية الواردة بالملحق الفني رقم

$$
\text { (2) و (3) يتضح ما يلي: (3) (2) }
$$

تقارب عزوم التوزيعات الاحتمالية البعدية لـعلمات النموذج في نهاية المحاولات المنكررة عند المحاولة رقم 2000 وذلك بدرجة ثقة 80\%، بحيث تستوي الخطوط ويصل النموذج لحل وحيد، ويصبح في حالة نوازن مستقر ، وذلك عند العزم الثاني m2 و العزم الثالث m3، أما الانحر اف البسيط بين الخطوط عند العزم الأول mo فيؤكد أن الاقتصاد المصري يثهد الآن حالات عدم الاستدامة المالية وعلى مدار فترة الدراسة، إلا أنها قد تكون قابلة للانعكاس في الأجل المتوسط حيث أن الاقتصاد المصري يسير في الآونة الأخيرة على المسار الصحيح للاستدامة المالية، وهو ما يجعل Univariate الخطوط نستوي مستقبلا كما يتضح من اختبارات الفحص أو التقارب الآحادي Convergence Diagnostics

" يُعَّ تقارب الخطوط في اختبارات الفحص أو التثقارب الآحادي عند المحاولة رقم 2000 وبدرجة ثقة 80\% هو المعيار الأمثل في خُوَارزم Monte 
النموذج مجتمعة على مسار الاستدامة المالية من خلال اختبارات الفحص أو الثقارب المتعدد Multivariate Convergence Diagnostic

$$
\text { عند العزمين الثاني و الثالثم20. }
$$

عدم تساوي القيم البعدية تقارب لمعلمات النموذج الخاصة عزوم التوزيعات الاحتمالية البعدية لمعلمات النموذج الخاصة بالتكلفة الحدية للاينه و التي بلغت قيمتها داخل الاقتصاد المصري و التي بلغت 50,. مع العائد الحدي المتحقق من الدين $\delta$ و التي بلغت قيمته 0.34 .وذلك كما يتضح من الخط الأسود بشكل Priors and posteriors الوارد بالملحق رقم (3)، وهو الأمر الذي ينم من خلاله قبول الفرضية الأساسية لهذه الدراسة و التي مفادها "أن الاقتصاد المصري قد شهد حالات عدم الاستدامة المالية على مدار فترة الدراسة"، إلا أن الانحر اف بين هذين القيميتين والذي يبلغ 16,. أقل من الانحراف الأولي المتوقع للنوزيعات القبلية لهذه المعلمات والذي بلغ 0.31، حيث سجلت $\sigma$ قيمة قبلية 0.67 في حين سجلت $\delta$ قيمة 0.36، وذلك كما يتضح من الخط الرمادي بالثكل ونتائج التقدير الواردة بالملحق؛ وهو الأمر الذي يمكن من خلاله التأكيد على النتيجة السابقة

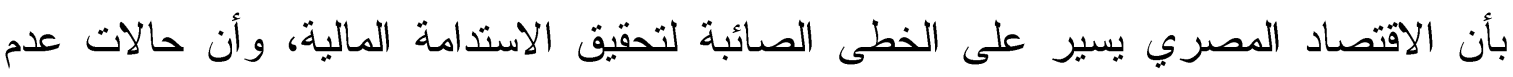
الاستدامة المالية قد تكون قابلة للانعكاس في الأجل المتوسط". انحر اف القيمة البعدية لمعلمة معدل نمو الدين العام في الأجل الطويل ح - و التي بلغت 1.01\% عن القيمة القبلية والمتلى لها لتحقيق الاستدامة المالية وهي 1\%، الأمر الذي يؤكد نفس النتائج السابقة ويجعل من فرضية قابلية الاستدامة المالية للانعكاس في الأجل المتوسط فرضية مقبولة في ضوء هذا الانحر اف البسيط بمقدار 0.01 \% بين القيم الفعلية داخل الاقتصاد المصري و القيم المثلى. إن لتأثير الصدمات العشو ائية التي يتعرض لها الاقتصاد المصري على مسار للاستدامة المالية النصيب الأكبر داخل نماذج التوازن العام العشوائية الديناميكية، حيث بلغت قيمة معلمة الصدمات العشوائية 0.970 بانحراف قدره 0.47 عن القيمة المنلى بأعلى انحر اف نم تسجيله عن باقي المعلمات الاقتصادية داخل النموذج، وهو الأمر الذي من خلاله يمكن القول بأن تصاعد حدة بـان

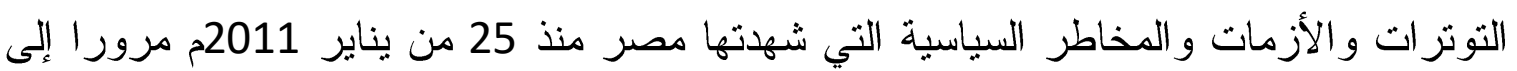
30 من يونيو 2013م أسفر عن المزيد من التذاعيات السلبية على الاقتصاد المصري، يأني في

\footnotetext{
${ }^{20}$ Pfeifer, J., "A Guide to Specifying Observation Equations for the Estimation of DSGE Models", January
} 2013, PP 1 - 81. 
مقدمتها حالة عدم الاستقرار الأمني وانعكاساتها السلبية على حركة السياحة والتجارة و النقل و الاستثمار، و انخفاض معدلات التثغيل و الإنتاج، بالإضافة إلى الانخفاض الحاد في أهم مصادر تمويل العجز في ميزان المدفوعات، ومنها عائدات السياحة وتحويلات العاملين بالخارج والاستثار ات الأجنبية المباشرة؛ الأمر الذي ساهم بشكل واضح في وصول الاقتصاد المصري لمر احل عدم الاستدامة المالية خلال فترة الدراسة، وهو ما تعبر عنه الخطوط المرتفعة بهذا الثكل التالي الناتج عن التتبؤ بمدى استجابة الدين العام المحلي الإجمالي كنسبة من الناتج المحلي الإجمالي للصدمات العشوائية داخل نماذج التوازن العام العشوائية الديناميكية مقارنة بالخطوط المنخفة و الوضع المستقر لاستجابة الدين العام المحلي الإجمالي كنسبة من الناتج المحلي الإجمالي للمتغيرات الاقتصادية داخل الاقتصاد المصري.

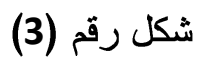

استجابة الدين العام المحلي الإجمالي كنسبة من الناتج المحلي الإجمالي

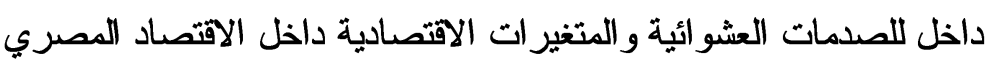

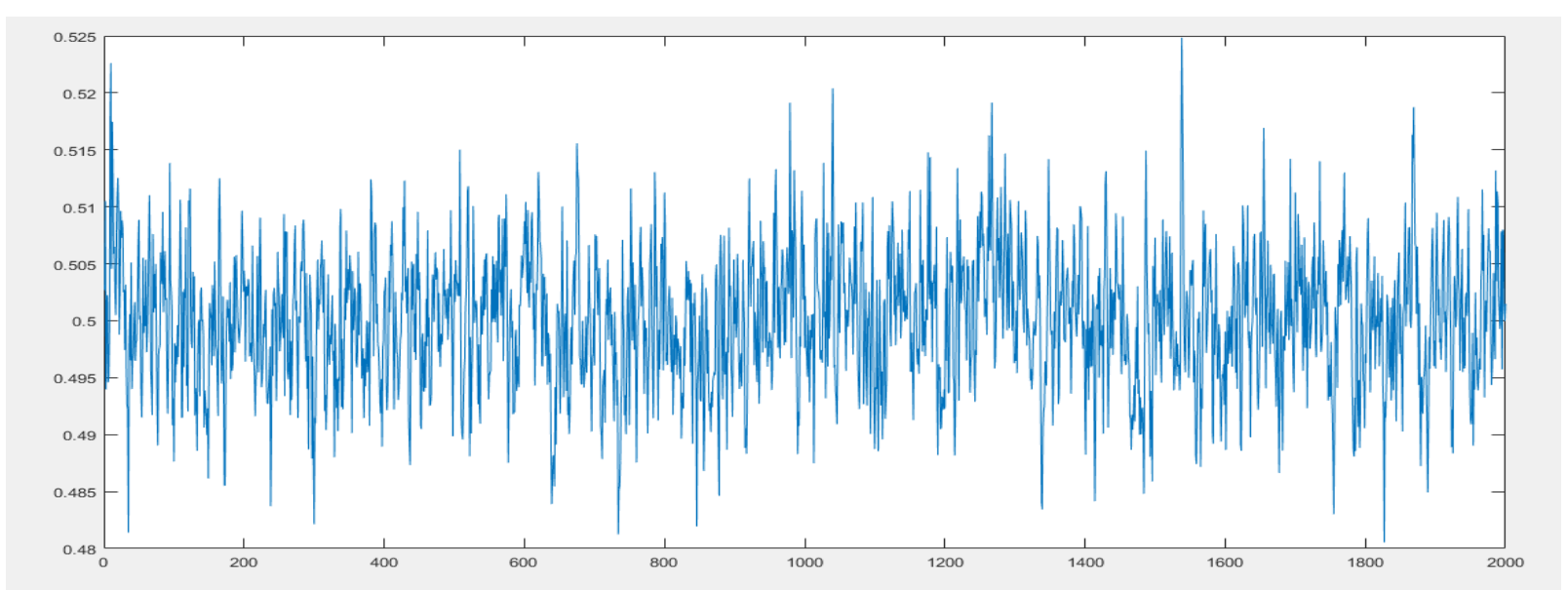

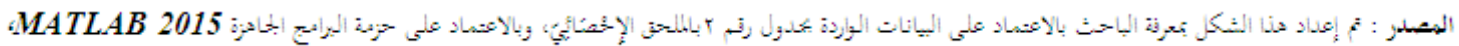
حزمة Dynare V:

8- السيناريو المرجعي والمستقبلي لمسار الاستدامة المالية للاقتصاد المصري من خلال نماذج التوازن العام العشوائية الديناميكية

أسفرت نتائج السيناريو السابق عن قبول النتيجة المرجعية الأولى وهي: "أن الاقتصاد المصري قد شهر حالات عدم الاستدامة المالية خلال فترة الدراسة". و إن هذه النتيجة وحدها كفيلة بضرورة إحداث تغيرات جذرية و هيكلية في نظم تمويل عجز الموازنة المطبقة، وتغير ات أخرى مناظرة في السياسات الاقتصادية 
المطبقة داخل الاقتصاد المصري، أما السيناريو المستقبلي والذي ظهرت بوادره من خلال السيناريو المرجعي حينما تم قبول النتيجة المرجعية الثانية وهي:- "أن الاقتصاد المصري يسير في الآونه الأخيرة

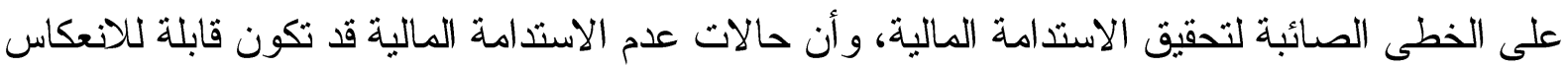
في الأجل المتوسط"-ـ؛ تدعمه نتائج التتبؤ بمسار الدين العام المحلي الإجمالي كنسبة من الناتج المحلي الإجمالي في السنو ات المقبلة من خلال نماذج التوازن العام العشو ائية الديناميكية، حيث اتضح من نتائج التتبؤ انخفاض نسبة الدين من85.3\% عام 2018م إلى 83.7\% عام 2020م و استقرار الاتجاه النزولي لهذه النسبة في الأجل المتوسط حول منوسط نسبة الدين خلال فترة الار اسة و التي بلغت 83.4\%، وذلك

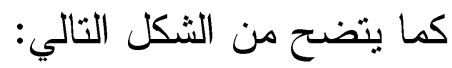

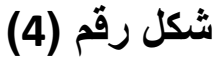

التبؤ بنسبة الدين العام داخل الاقتصاد المصري خلال الفترة من عام 2020م وحتى عام 2025م الاينماد الفمام

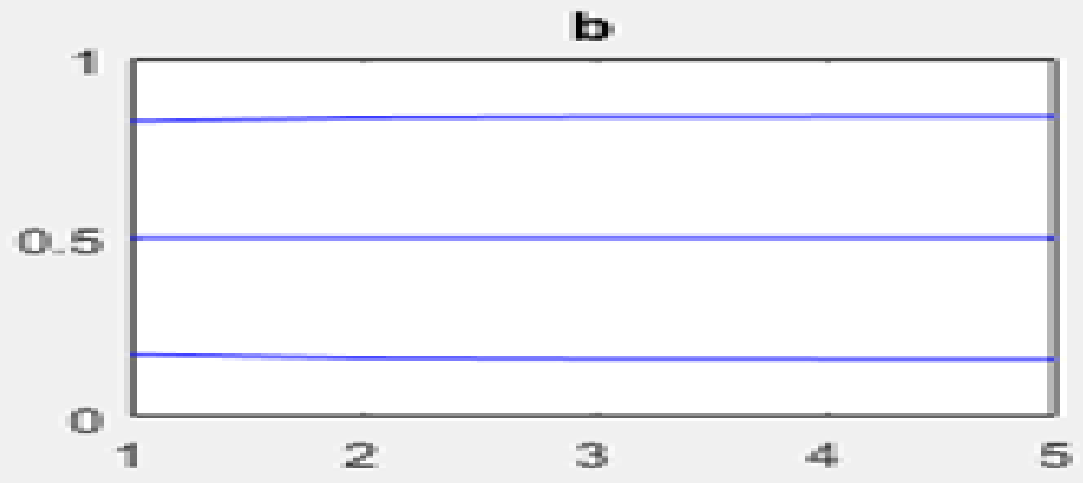

المصدر: تم إعاد هذا الثنكل بمعرفة الباحثة بالاعتماد على البيانات الواردة بجدول رقم 2 بالملحق الإحصائي، وبالاعتماد على حزمة

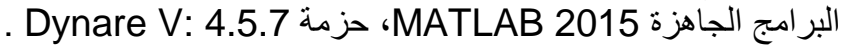

و على إثر ما أسفرت عنه نتائج السيناريو المرجعي و المستقبلي السابق، وفي ضوء التسليم بمنطقية أن السياسات الاقتصادية المستدامة تسعى إلى تحقيق هدف تتعامل معهم السلطات الاقتصادية - غالبا بمنأى عن الأهداف الاقتصادية العامة، وهو : استدامة الوضع المالي (وذلك من خلال تحقيق مستوى ملائم ومستقر في نسبة الدين العام إلى الناتج المحلي الإجمالي، وبما يحقق المستوى الملائم لعجز الموازنة ويتتاسب مع حجم التعديل المالي المتاح لتحقيق الاستقر ار المالي )؛ فإنه يمكن الوصول لبعض التوصيات لمساعدة صانعي القر ار على تثكيل الاستر اتيجيات المستقبلية لتصميم نماذج الموازنة العامة المضادة للصدمات؛ وذلك بهدف التوصل إلى النموذج المناسب للاقتصاد المصري الذي يمكن من خلاله 
التسيق بين السياسات النقدية والمالية و الهيكلية تحت مظلة نظام معدل الصرف الأكثر قدرة على امتصاص الصدمات؛ تمهيدا لتحقيق الاستدامة المالية للاقتصاد المصري، على النحو التالي: (1) ترسيخ المكاسب التي تحقت بجهذ شاق في سبيل استقر ار الاقتصاد المصري وفقا لبرنامج الإصدلاح الاقتصادي منذ نوفمبر 2016م، وتعجيل تتفيذ الإصلاحات الهيكلية للاستفادة من "تسهيل الصندوق المددد EFF لإطلاق إمكانات الاقتصاد المصري؛ وذلك في ضوء قبول نتائج السيناريو المستقبلي بأن الاقتصاد المصري يسير في الآونة الأخيرة على الخطى الصائبة لتحقيق الاستدامة المالية، وأن هذا الأمر لا يستدعي ضرورة إحداث تغير ات جذرية و هيكلية في نظم تمويل عجز المو ازنة المطبقة وتغيرات جذرية أخرى مناظرة في السياسات الاقتصادية الكلية المطبقة داخل الاقتصاد المصري، و إنما بستدعي ترسيخ وتحسين أداء السياسات المطبقة حاليا. (2) تتضمن مراحل الوصول إلى الاستدامة المالية الأجل المتوسط، تفعيل استر اتيجية لإدارة الدين العام من خلال تفعيل جهة رقابية تشرف على الدين العام وفقا لما أسفرت عنه نتائج نماذج النوازن العام العشو ائية الديناميكية، بحيث تحاول تخفيض النكلفة الحدية للاين م و التي بلغت قيمتها داخل الاقتصاد المصري و التي بلغت 0.50، وزيادة العائد الحدي المتحقق من الدين $\delta$ و التي بلغت قيمته 34,.، بحيث تتبع هذه الجهة الرقابية أسباب الإصدار والجهة الموجه لها هذا الإصدار، و التأكد من أن هذا الدين تم استخدامه بكفاءة، و إحكام السيطرة على مدفوعات خدمة الدين العام، ووضع سقوف عليا لا يمكن تخطيها. (3) إن انخفاض القيمة البعدية للتكلفة الحدية للدينم و التي بلغت 0.50 عن القيمة القبلية لها وهي 0.67 توحي بأن الاقتصاد المصري على الطريق الصحيح الذي تعالت به الأصو ات الداعية إلى تخفيض التكلفة الحدية للاين من خلال تطوير سوق الأوراق المالية ومد فترات استحقاق الدين و عمل تتوع في اختيار ات إصدار الدين، ولكن ما زال الاقتصاد المصري يحتاج المزيد في سبيل رفع العائد الحدي المتحقق من الدين $\delta$ و التي بلغت قيمته 34,. من خلال الحرص على إنتاجية الدين وثوجيه الإنفاق إلى أنشطة ثدر من العائد ما يحدث التقارب المنشود بين التكلفة الحدية للاين و العائد الحدي من إصداره لتحقيق المسار الصحيح للاستدامة المالية للاقتصاد المصري. (4) يتطلب الحفاظ على السيناريو المستقبلي لمسار الاستدامة المالية للاقتصاد المصري مزيد من الثفافية و الإفصاح، وذلك بإصدار تقارير دورية عن مسار الاستدامة المالية؛ استنادا إلى المؤشرات اليقينية المستخدمة داخل هذه الدر اسة وهي: مؤشر الفائض أو العجز المالي الأولي، و مؤشر الفجوة الضريبية، بالإضافة إلى المؤشرات غير اليقينية المستوحاة من نماذج التوازن العام العشو ائية الديناميكية، على أن 
تتضمن كافة الالتزامات المعلنة وغير المعلنة من ضمانان حكومية ومتأخرات مستحقة على الحكومة وتقديم بيانات تقصيلية عنها، وتحليل المخاطر التي يمكن أن تحيط بتتفيذ الموازنة التي يفضل إعدادها على أساس منوسط الأجل بديلا عن أسلوب الموازنة السنوي. أضف إلى ما سبق ضرورة اتباع سياسة مالية تتبنى مفهوم الحوكمة في الموازنة العامة للدولة بأبعادها المختلفة من مساعلة وشفافية أو إفصاح ومشاركة، ووجود آلية للتنسيق بين هذه السياسات النقدية و السياسات المالية لضمان السيطرة على العجز المالي، والنمو في القاعدة النقدية، ونمو الائمان،

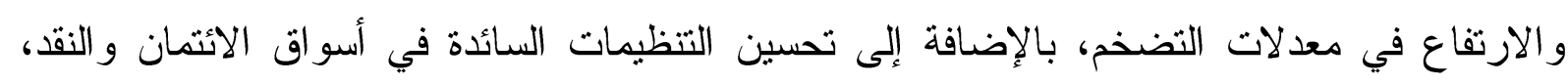
و إصداح النظم الضريبية والجمركية، وتعزيز درجة التكامل والعمق المالي؛ الأمر الذي يؤدي في نهاية المطاف إلى تحسن الأداء الاقتصادي المصري وزيادة فعالية السياسات الاقتصادية الكلية المطبقة داخله؛ ومن ثم المضي قدما نحو تحقيق الاستدامة المالية. وينبغي على السلطات الاقتصادية أن ثأخذ في اعتبار ها كافة التغير ات الهيكلية السابقة بنظرة أكثر شمو لا وتكاملا في إطار نوع من التتاغم و التتسيق و التكامل للتغلب على العجز المالي المصري، فتحقيق الاستدامة المالية لن بأتي إلا من خلال نظم مثلى لإدارة

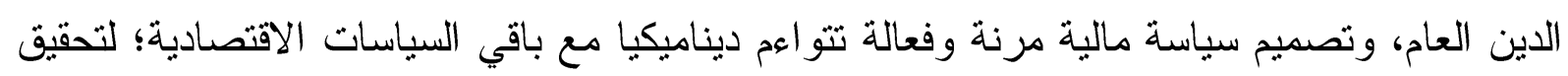
استقرار اقتصادي يمهد الطريق لتحقيق الاستدامة المالية للاقتصاد المصري. 


\title{
الملحق الفني والإحصائي للدراسة
}

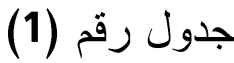

متغير ات الخوارزميات المستخدمة لتقدير مؤشر الفائض أو العجز المالي الأولي ومؤشر الفجوة الضريبية داخل الاقتصاد المصري

\begin{tabular}{|c|c|c|c|c|c|c|c|c|}
\hline $\begin{array}{l}\text { مؤشر الفجوة الضريبية } \\
t_{t}+\left(r_{t}-n_{t}\right) b_{t}-g_{t}\end{array}$ & 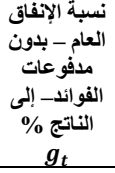 & 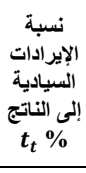 & 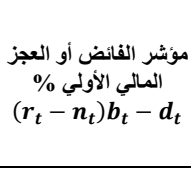 & 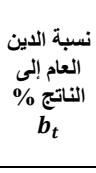 & 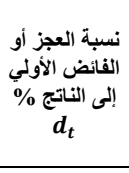 & $\begin{array}{c}\text { معدلات النموي } \\
\text { \% } \\
n_{t}\end{array}$ & $\begin{array}{c}\text { الفائدة } \\
\text { الحقيقية } \\
\text { \% } \\
r_{t}\end{array}$ & السنة \\
\hline 28.31- & 30.29 & 15.84 & 25.46- & 98.54 & 11.60 & 4.80 & 9.26- & 1990 \\
\hline 26.15- & 31.97 & 14.45 & 17.68- & 87.94 & 9.05 & 3.70 & 6.12- & 1991 \\
\hline 9.14- & 29.04 & 18.92 & 3.53 & 80.88 & $2.55-$ & 1.90 & 3.11 & 1992 \\
\hline 8.01- & 26.63 & 19.50 & 4.45 & 77.78 & 5.32- & 2.50 & 1.38 & 1993 \\
\hline 5.39- & 24.40 & 19.94 & 6.93 & $\begin{array}{l}76.07 \\
\end{array}$ & 7.86- & 3.90 & 2.68 & 1994 \\
\hline 7.34- & 22.89 & 18.43 & 3.55 & 70.62 & 6.42- & 4.70 & 0.63 & 1995 \\
\hline 6.04- & 22.36 & 18.02 & 4.37 & 70.24 & 6.07- & $\begin{array}{l}5.00 \\
\end{array}$ & 2.58 & 1996 \\
\hline 4.47- & 20.78 & 16.35 & 5.29 & 69.16 & 5.33- & 5.30 & 5.24 & 1997 \\
\hline 3.41- & 20.95 & 16.57 & $\begin{array}{l}5.50 \\
\end{array}$ & 70.71 & 4.53- & 4.10 & 5.48 & 1998 \\
\hline 4.82- & 22.51 & 17.16 & 3.17 & 76.79 & $2.65-$ & 5.40 & 6.08 & 1999 \\
\hline 5.30- & 22.18 & 16.35 & 2.24 & 77.78 & 1.71- & 5.90 & 6.58 & 2000 \\
\hline 3.57- & 22.62 & 15.73 & 3.60 & 87.44 & 0.28- & 3.40 & 7.20 & 2001 \\
\hline 4.11- & 22.07 & 14.72 & 3.43 & 93.02 & 0.20- & 3.20 & 6.68 & 2002 \\
\hline 6.03- & 21.79 & 14.69 & 1.41 & 94.90 & 0.35- & 3.10 & 4.22 & 2003 \\
\hline 18.62- & 20.85 & 14.70 & 14.48- & 95.29 & 2.00 & 4.23 & 8.86- & 2004 \\
\hline 10.69- & 23.84 & 14.97 & 4.21- & 99.64 & 2.40 & 4.60 & 2.78 & 2005 \\
\hline 20.87- & 28.91 & 16.83 & 12.73- & 101.08 & 3.94 & 6.90 & $1.79-$ & 2006 \\
\hline 20.82- & 27.64 & 16.09 & 10.26- & 88.82 & 0.98 & 7.05 & 3.39- & 2007 \\
\hline 28.41- & 29.85 & 16.04 & 15.85- & 76.97 & 1.24 & 7.18 & 11.81- & 2008 \\
\hline $21.75-$ & 30.60 & 16.42 & 9.49- & 75.98 & 1.91 & 4.70 & $5.27-$ & 2009 \\
\hline $20.72-$ & 28.20 & 14.82 & 9.57- & 77.24 & 2.23 & 5.10 & 4.40- & 2010 \\
\hline 18.15- & 27.13 & 14.67 & 9.46- & 79.77 & 3.77 & 1.94 & $5.20-$ & 2011 \\
\hline 13.24- & 24.05 & 12.11 & 4.94- & 72.27 & 3.63 & 2.20 & 0.40 & 2012 \\
\hline 15.87- & 25.83 & 13.05 & 7.91- & $\begin{array}{l}79.35 \\
\end{array}$ & 4.82 & 2.10 & $1.80-$ & 2013 \\
\hline 19.41- & 26.60 & 11.80 & 8.34- & 82.36 & 3.73 & 2.20 & 3.40- & 2014 \\
\hline 19.26- & 24.78 & 12.37 & 10.34- & 85.57 & 3.49 & 3.40 & $4.60-$ & 2015 \\
\hline 18.67- & 23.22 & 13.17 & 12.21- & 97.99 & 3.58 & 2.30 & $6.50-$ & 2016 \\
\hline 30.51- & 23.48 & 13.55 & 22.43- & 92.71 & 1.85 & 3.60 & 18.60- & 2017 \\
\hline 12.98- & 20.73 & 14.49 & 6.63- & 85.29 & 0.11- & 5.20 & $2.70-$ & 2018 \\
\hline
\end{tabular}

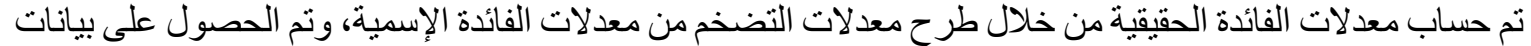

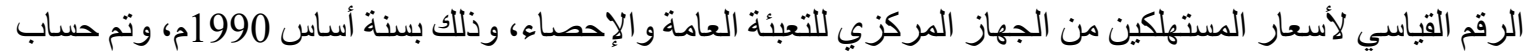

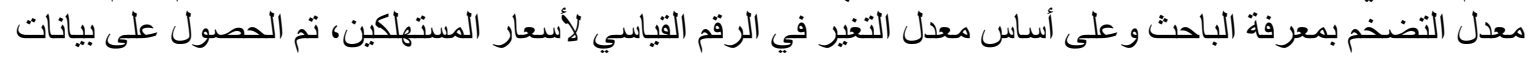

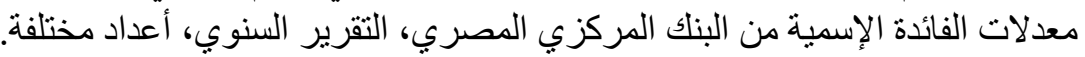

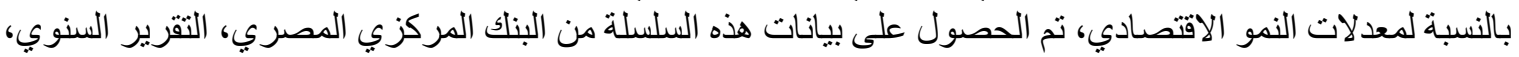
أعداد مختلفة.

بالنسبة لنسبة الدين العام إلى الناتج المحلي الإجمالي، تم الحصول على بيانات هذه السلسلة من البنك المركزي المصري، التقرير السنوي، أعداد مختلفة.

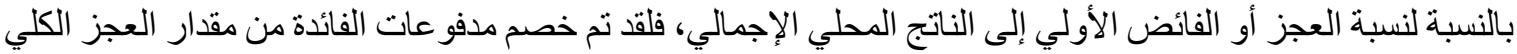

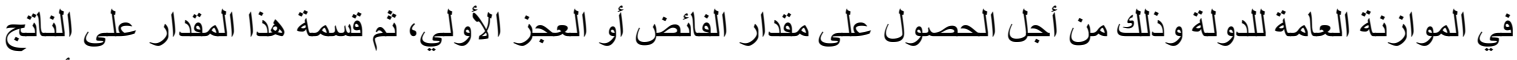

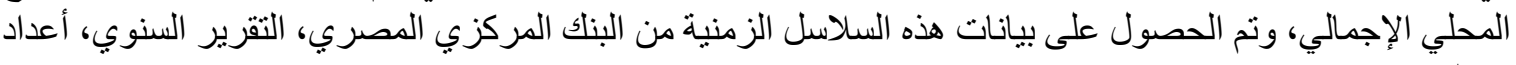

مختلفة.

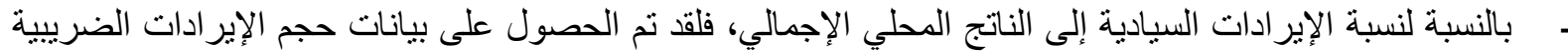

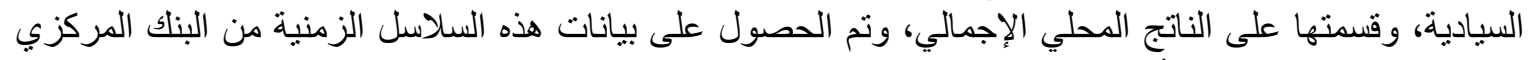

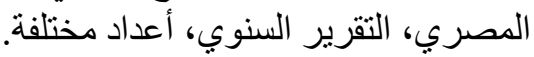

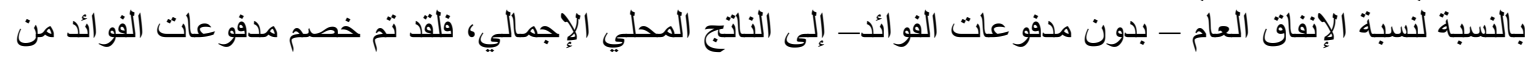

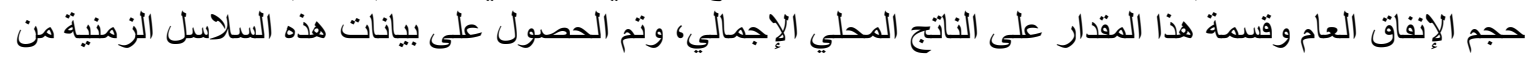

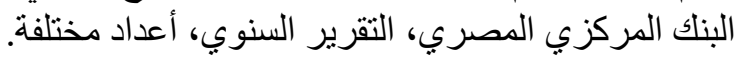




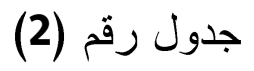

منغير ات نماذج النو ازن العام العشو ائية الديناميكية و المعادلات السلوكية

لقياس مسار الاستدامة المالية داخل الاقتصاد المصري

(القيم بالمليار جنيه)

\begin{tabular}{|c|c|c|c|c|c|c|}
\hline حجم الإنفاق & مدفوعات خدمة & $\begin{array}{c}\text { العام إلى الناتج } \\
\text { \% } \\
\text { b }\end{array}$ & $\begin{array}{c}\text { بالأسعار الجاريّية الإنفاقي } \\
\text { C }\end{array}$ & 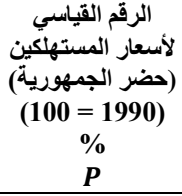 & 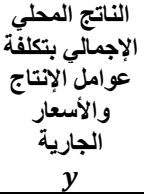 & السنة \\
\hline 34.23 & 6.50 & 98.54 & 68.90 & 100.00 & 91.54 & 1990 \\
\hline 42.17 & 7.00 & 87.94 & 82.20 & 119.72 & 110.01 & 1991 \\
\hline 47.56 & 9.50 & 80.88 & 101.00 & 136.03 & 131.06 & 1992 \\
\hline 52.22 & 13.30 & 77.78 & 115.00 & 152.51 & 146.16 & 1993 \\
\hline 56.26 & 16.50 & 76.07 & 130.50 & 164.92 & 162.97 & 1994 \\
\hline 58.53 & 14.80 & 70.62 & 151.90 & 178.72 & 191.01 & 1995 \\
\hline 63.89 & 16.00 & 70.24 & 176.50 & 191.64 & 214.19 & 1996 \\
\hline 66.83 & 15.50 & 69.16 & 205.20 & 200.48 & 247.03 & 1997 \\
\hline 70.78 & 14.90 & 70.71 & 220.40 & 207.54 & 266.76 & 1998 \\
\hline 80.00 & 16.40 & 76.79 & 230.80 & 213.89 & 282.58 & 1999 \\
\hline 88.60 & 18.60 & 77.78 & 258.00 & 219.69 & 315.67 & 2000 \\
\hline 96.12 & 20.90 & 87.44 & 270.00 & 224.58 & 332.54 & 2001 \\
\hline 101.15 & 22.90 & 93.02 & 279.50 & 230.74 & 354.56 & 2002 \\
\hline 111.91 & 26.80 & 94.90 & 304.90 & 240.53 & 390.62 & 2003 \\
\hline 128.32 & 33.20 & 95.29 & 347.80 & 280.32 & 456.32 & 2004 \\
\hline 158.48 & 37.70 & 99.64 & 385.30 & 293.86 & 506.51 & 2005 \\
\hline 207.81 & 39.80 & 101.08 & 436.10 & 316.47 & 581.14 & 2006 \\
\hline 244.02 & 47.70 & 88.82 & $\begin{array}{l}539.20 \\
\end{array}$ & 346.49 & 710.39 & 2007 \\
\hline $\begin{array}{l}305.80 \\
\end{array}$ & 50.53 & 76.97 & 647.60 & 409.92 & 855.30 & 2008 \\
\hline 356.94 & 52.81 & 75.98 & 793.10 & 458.17 & 994.06 & 2009 \\
\hline 396.77 & 72.33 & 77.24 & 899.80 & 507.19 & 1150.59 & 2010 \\
\hline 440.41 & 85.08 & 79.77 & 1036.10 & 567.04 & 1309.91 & 2011 \\
\hline 516.42 & 104.44 & 72.27 & 1351.70 & 608.43 & $\mathbf{1 7 1 3 . 1 5}$ & 2012 \\
\hline 644.08 & 147.00 & 79.35 & 1502.70 & 668.06 & 1924.81 & 2013 \\
\hline 759.85 & 173.15 & 82.36 & 1766.60 & 735.53 & 2205.59 & 2014 \\
\hline 805.93 & 193.01 & 85.57 & 2014.50 & 819.38 & 2473.10 & 2015 \\
\hline 864.56 & 243.64 & 97.99 & 2251.20 & 934.09 & 2674.41 & 2016 \\
\hline 1116.99 & 316.60 & 92.71 & $\mathbf{3 0 5 7 . 9 0}$ & 1212.45 & 3409.50 & 2017 \\
\hline 1335.98 & 437.36 & 85.29 & 3791.60 & 174.74 & 4333.90 & 2018 \\
\hline
\end{tabular}

- تم الحصول على بيانات الناتج المحلي الإجمالي بالأسعار الجارية، وحجم الإنفاق الاستهلاكي، من وزارة التخطيط، التقرير السنوي للحسابات القومية، أعداد مختلفة.

بالنسبة لحجم الإنفاق العام، ومدفوعات خدمة الدين، فلقد تم الحصول على بيانات هذه السلاسل الزمنية من البنك المركزي المصري، التقرير السنوي، أعداد مختلفة. 


\title{
الملحق الفني رقم (1) \\ قائمة الأو امر البرمجية ونتائج تقدير نماذج التوازن العام العشوائية الديناميكية

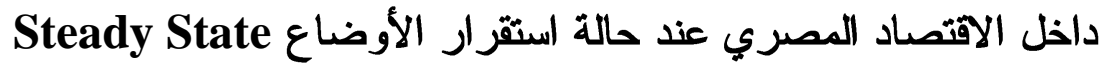

\author{
varyp c b rb g z; \\ varexo eps; \\ parameters cdelta, eta, sig, cbeta, cgam, \\ crho, csigma; \\ cdelta $=0.36$ \\ eta $=0.05$; \\ sig = 0.67; \\ cbeta $=0.99$; \\ $\operatorname{cgam}=1$; \\ crho $=0.5$ \\ csigma $=0.02$; \\ model; \\ $(1-$ cdelta/cdelta $) *(c+g) \wedge(1+$ eta $)=p+b ;$ \\ $($ cgam $/ 1-b)=(g / y)$; \\ $\mathrm{g}^{\wedge} 1$-sig $=\left((1+\mathrm{c}+\mathrm{g})^{\wedge} \text { cbeta }\right)^{*}\left(\mathrm{~g}^{\wedge} 1-\mathrm{sig}\right)$; \\ $\mathbf{y}=-\mathbf{r b}+\operatorname{cgam}^{*} \mathbf{b}(+1)+\mathrm{c}+\mathrm{g}$; \\ $\mathrm{b}=\exp (\mathrm{z}) *(\mathrm{~g} / \mathrm{y})$ \\ $\mathbf{r b}=\exp (\mathrm{z}) *(\mathbf{b} / \mathbf{g})$; \\ $\mathrm{z}=\operatorname{crho}^{*} \mathrm{z}(-1)+\mathrm{eps}$; \\ end; \\ initval; \\ $\mathbf{y}=9$; \\ $\mathbf{p}=\mathbf{8}$ \\ $\mathbf{c}=\mathbf{5}$; \\ $\mathrm{b}=\mathbf{1 0}$; \\ rb = 1; \\ $\mathrm{g}=4$; \\ $\mathrm{z}=\mathbf{0}$; \\ end; \\ steady; \\ shocks; \\ var eps $=\operatorname{csigma}^{\wedge} 2$; \\ end; \\ stoch_simul(order=2, \\ irf $=\mathbf{4 0}$, \\ periods $=2000$ );
}
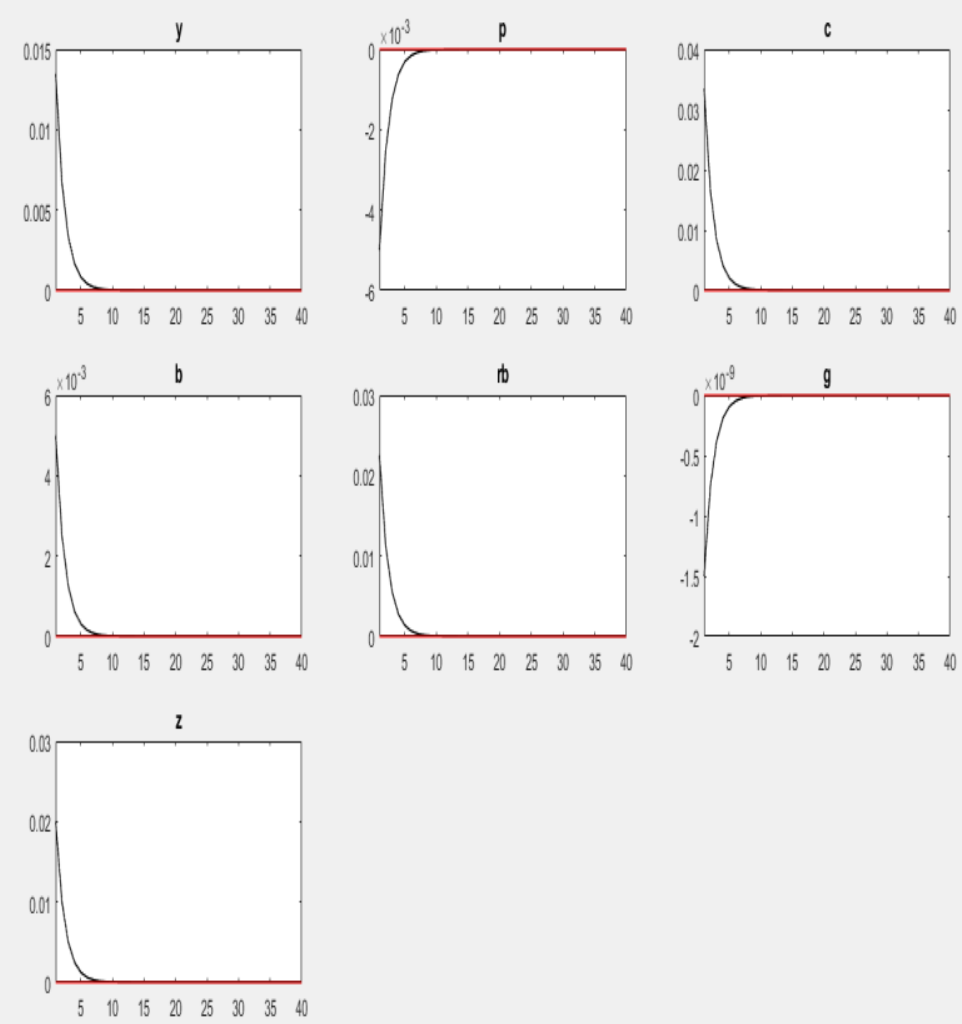
Found 7 equation(s).

Evaluating expressions... done

computing static model derivatives:

- order 1

computing dynamic model derivatives:

- order 1

- order 2

Processing outputs ...

done

Preprocessing completed.

STEADY-STATE RESULTS:

$\begin{array}{ll}y & 1.34 \\ p & -0.5 \\ c & 0.916268 \\ b & 0.5 \\ r b & 0.746269 \\ g & 0.67 \\ z & 0\end{array}$

MODEL SUMMARY

Number of variables:

Number of stochastic shocks: 1

Number of state variables: 1

Number of jumpers:

Number of static variables: 5

MATRIX OF COVARIANCE OF EXOGENOUS SHOCKS

Variables

eps
0.000400

eps

POLICY AND TRANSITION FUNCTIONS

\begin{tabular}{|c|c|c|c|c|c|}
\hline $\begin{array}{l}\text { Constant } \\
z(-1) \\
\text { eps } \\
z(-1), z(-1) \\
\text { eps,eps } \\
z(-1), \text { eps }\end{array}$ & & $\begin{array}{r}y \\
0000 \\
5000 \\
0000 \\
3750 \\
5000 \\
5000\end{array}$ & $\begin{array}{r}p \\
-0.500000 \\
-0.125000 \\
-0.250000 \\
0 \\
0 \\
0\end{array}$ & $\begin{array}{r}{ }^{c} \\
0.916268 \\
0.832201 \\
1.664403 \\
0.270317 \\
1.081269 \\
1.081269\end{array}$ & $\begin{array}{r}b \\
0.500000 \\
0.125000 \\
0.250000 \\
0 \\
0 \\
0\end{array}$ \\
\hline VOMENTS OF & ATED VARIAB & & & & \\
\hline $\begin{array}{l}\text { VARIABLE } \\
y \\
p \\
c \\
b \\
r b \\
g \\
z\end{array}$ & $\begin{array}{r}\text { MEAN } \\
1.340053 \\
-0.499950 \\
0.916539 \\
0.499950 \\
0.746461 \\
0.670000 \\
-0.000198\end{array}$ & $\begin{array}{l}\text { STD. DEV. } \\
0.015797 \\
0.005892 \\
0.039250 \\
0.005892 \\
0.026398 \\
0.000000 \\
0.023569\end{array}$ & $\begin{array}{l}\text { VARIANCE } \\
0.000250 \\
0.000035 \\
0.001541 \\
0.000035 \\
0.000697 \\
0.000000 \\
0.000555\end{array}$ & $\begin{array}{r}\text { SKEWNESS } \\
0.113933 \\
-0.036091 \\
0.137309 \\
0.036091 \\
0.139970 \\
0.025628 \\
0.036091\end{array}$ & $\begin{array}{l}\text { KURTOSI } \\
0.240811 \\
0.196789 \\
0.25752 \\
0.196789 \\
0.259528 \\
0.17458 \\
0.196789\end{array}$ \\
\hline
\end{tabular}

CORRELATION OF SIMULATED VARIABLES

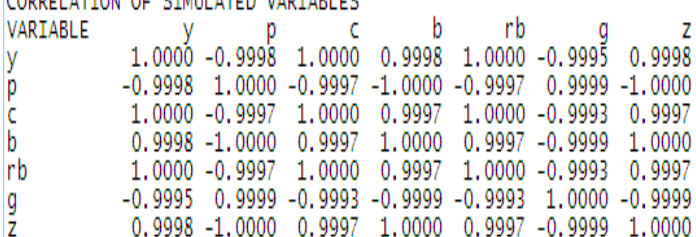

AUTOCORRELATION OF SIMULATED VARIABLES

$\begin{array}{lrrrrr}\text { VARIABLE } & 1 & 2 & 3 & 4 & 5 \\ y & 0.5438 & 0.2747 & 0.1095 & 0.0357 & 0.0407 \\ p & 0.5449 & 0.2764 & 0.1109 & 0.0366 & 0.0415 \\ c & 0.5435 & 0.2741 & 0.1091 & 0.0355 & 0.0405 \\ b & 0.5449 & 0.2764 & 0.1109 & 0.0366 & 0.0415 \\ b & 0.5435 & 0.2741 & 0.1091 & 0.0354 & 0.0404 \\ r b & 0.5456 & 0.2777 & 0.1119 & 0.0372 & 0.0421 \\ g & 0.5449 & 0.2764 & 0.1109 & 0.0366 & 0.0415\end{array}$

Total computing time : Oh00m03s 


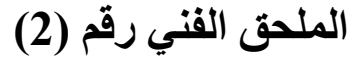

اختبارات الفحص الأحادي MCMC و الفحص المتعدد MCD لمعلمات النموذج
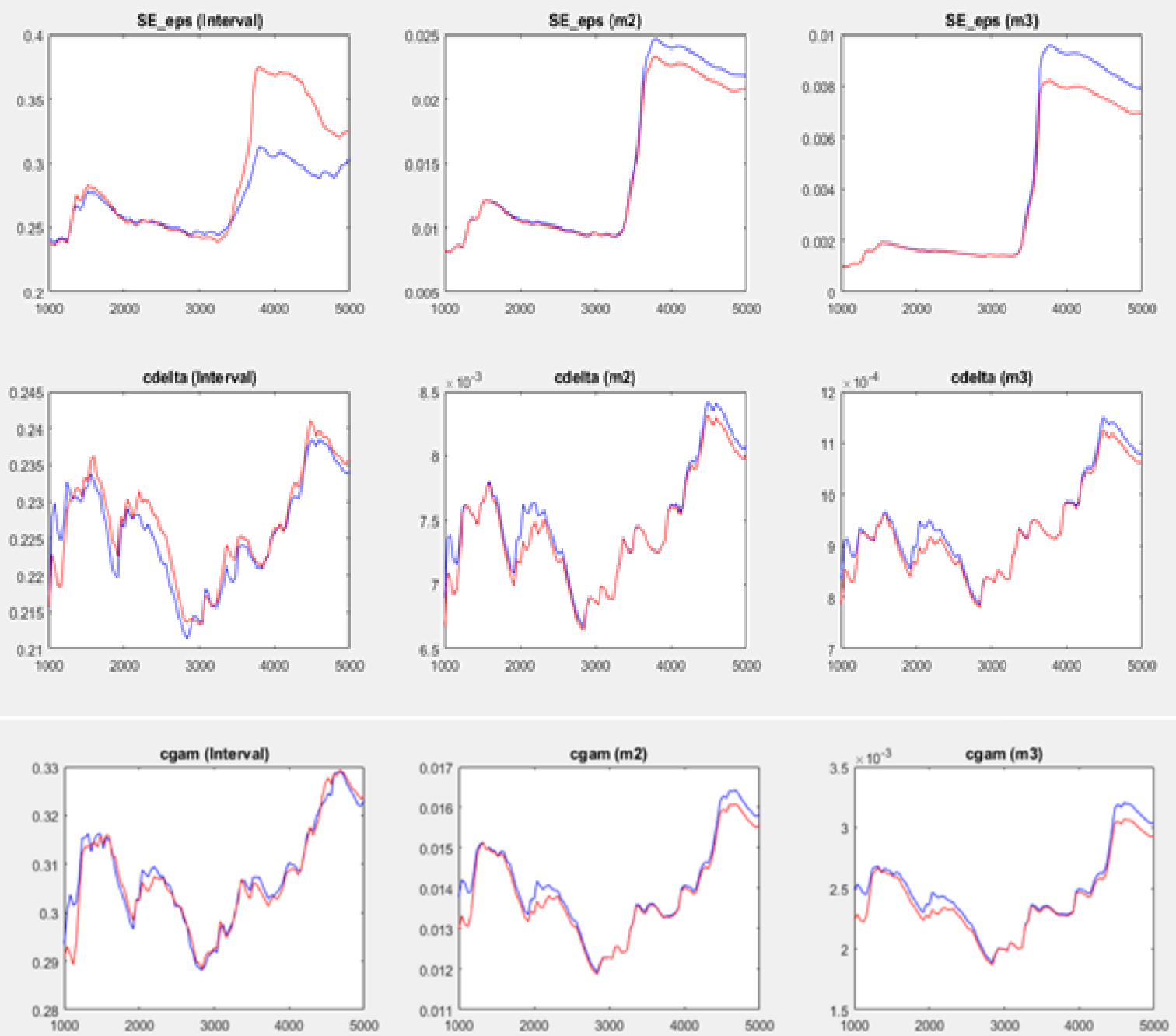

MCMC univariate convergence diagnostic (Brooks and Gelman, 1998)
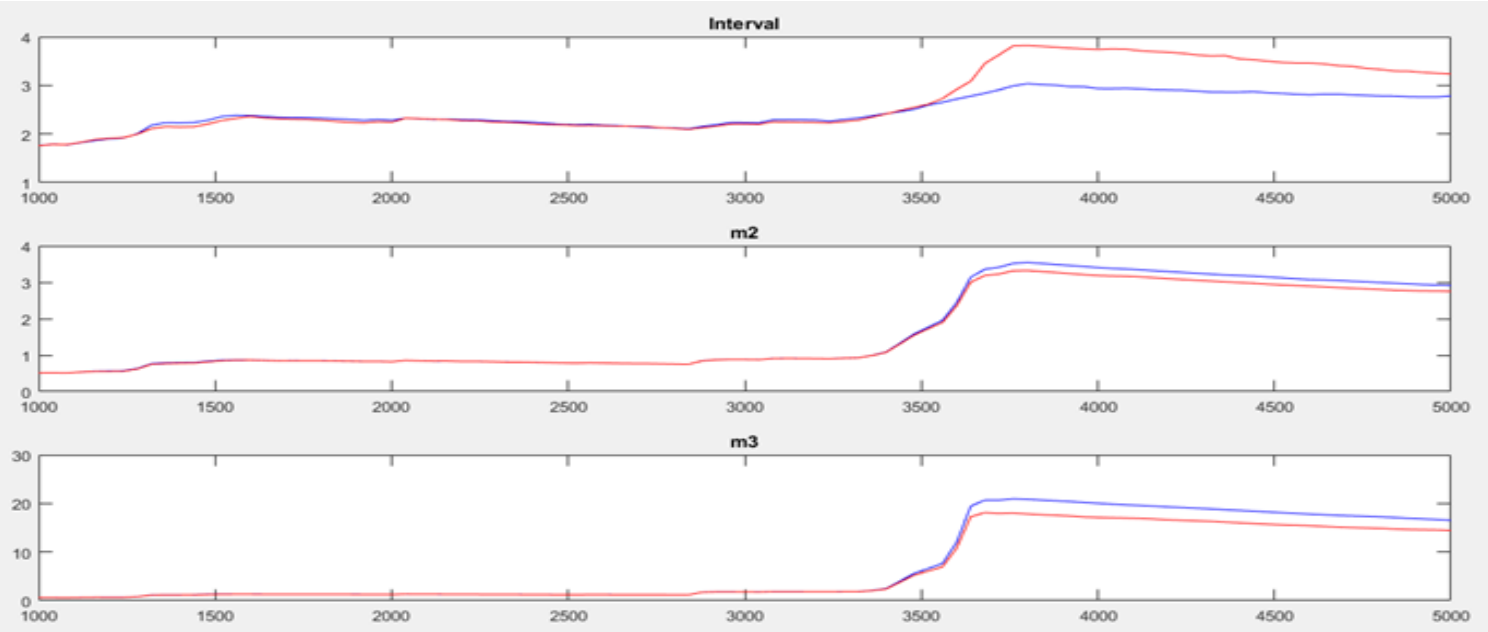

Multivariate convergence diagnostic 


\section{الملحق القني رقم (3)}

\section{قائمة الأوامر البرمجية ونتائج تقدير نماذج التوازن العام العثوائية الديناميكية داخل الاقتصاد المصري بشرط وجود متجه المتغيرات المشاهدة}

$\operatorname{var}$ y p c b rb g z;

varexo eps;

parameters cdelta, eta, sig, cbeta, cgam, crho, csigma; cdelta $=0.36$;

eta $=0.05$;

sig $=0.67$

cbeta $=0.9$

cgam $=1$;

crigma $=0.0$

model;

$(1-\text { cdelta/cdelta })^{*}(\mathbf{c}+\mathrm{g})^{\wedge}(1+$ eta $)=\mathrm{p}+\mathrm{b}$;

$(\operatorname{cgam} / \mathbf{1}-\mathbf{b})=(\mathrm{g} / \mathbf{y})$;

$\mathrm{g}^{\wedge} 1-\mathrm{sig}=\left((1+\mathrm{c}+\mathrm{g})^{\wedge} \text { cbeta }\right)^{*}\left(\mathrm{~g}^{\wedge} 1-\mathrm{sig}\right)$;

$\mathbf{y}=-\mathbf{r b}+\operatorname{cgam} * \mathbf{b}(+1)+\mathbf{c}+\mathrm{g}$

$\mathrm{b}=\exp (\mathrm{z}) *(\mathrm{~g} / \mathrm{y})$;

$\mathbf{r b}=\exp (\mathbf{z}) *(\mathbf{b} / \mathbf{g})$

$z=\operatorname{crho}^{*} z(-1)+$ eps;

end;

initval;

$\mathrm{y}=\mathbf{0 . 9 8}$

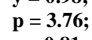

$\mathrm{c}=\mathbf{0 . 8 1}$

$\mathrm{b}=\mathbf{0 . 8 4}$

$\mathrm{rb}=0.08$;

$\mathrm{g}=3.19$

$\mathrm{g}=3$.

$\mathrm{z}=\mathbf{0}$

end;

steady;

var eps $=$ csigma^ $^{\wedge}$

end;

varobs b;

imated_params;

delta, beta_pdf, $0.36,0.09$,

tderr eps, inv_gamma_pdf, 0.1 , inf

end;

Priors and posteriors
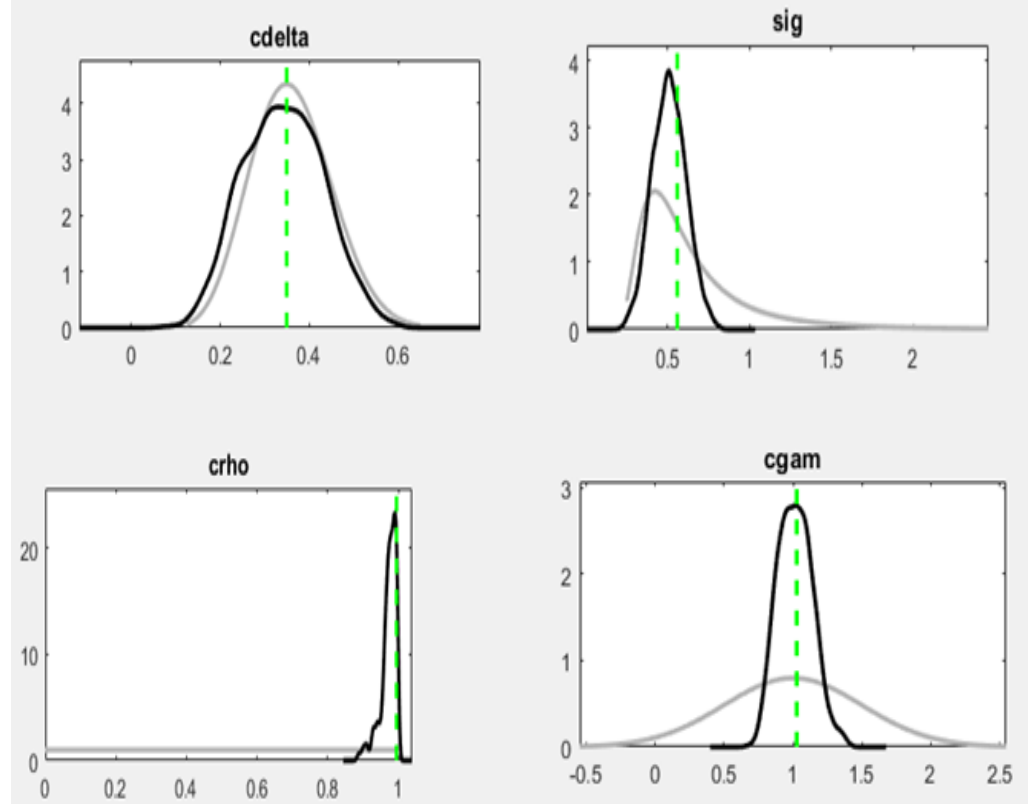

conditional_forecast $\left(\right.$ parameter $\_$set $=$calibration

mh_replic $=5000, \mathrm{mh}$ nblocks $=2, \mathrm{mh}$ jscale $=0.2$, mode_check,bayesian_irf);

conditional_forecast_paths;

var b;

values $0.7,0.84$

end;

controlled_varexo $=(\mathrm{eps})$, replic $=5000)$;

plot_conditional_forecast (periods $=10)$ b

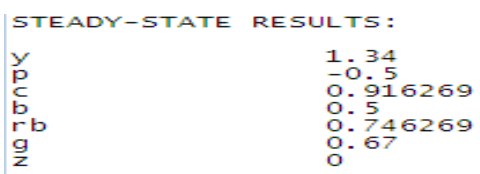

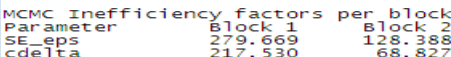

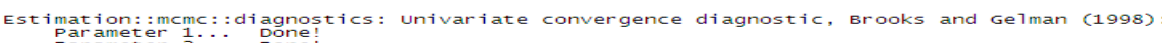

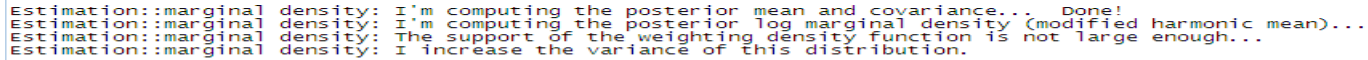

Estimation: :marginal density: There's probably a problem with the modified harmonic mean estimator.

ESTIMATION RESULTS

Log data density is -0.670243

parameters mean post. mean $90 \%$ HPD interval prior pstdev

$\begin{array}{lllllll}\text { cdelta } & 0.360 & 0.3406 & 0.1969 & 0.4883 & \text { beta } & 0.0900\end{array}$

standard deviation of shocks
prior mean post. mean $90 \%$ HPD interval prior pstdev

eps computing time: : o.ho1m48s $0.5821 \quad 0.9594$ invg Inf

\begin{tabular}{|c|c|c|c|c|c|c|c|}
\hline $\begin{array}{l}\text { param } \\
\text { cgam }\end{array}$ & $\begin{array}{l}\text { ters } \\
\text { prior }\end{array}$ & $\begin{array}{l}\text { mean } \\
1.000\end{array}$ & $\begin{array}{r}\text { post. mean } \\
1.0153\end{array}$ & $\begin{array}{l}90 \% \mathrm{HPD} \\
0.8127\end{array}$ & $\begin{array}{r}\text { interval } \\
1.2150\end{array}$ & $\begin{array}{l}\text { prior } \\
\text { norm }\end{array}$ & $\begin{array}{l}\text { pstder } \\
0.5000\end{array}$ \\
\hline & prior & mean & post. mean & $90 \% \mathrm{HPD}$ & interval & prior & pstdev \\
\hline crho & & 0.500 & 0.9727 & 0.9411 & 0.9999 & unif & 0.2887 \\
\hline & prior & mean & post. mean & $90 \% \mathrm{HPD}$ & interval & prior & pstdev \\
\hline sig & & 0.670 & 0.5082 & 0.3365 & 0.6725 & invg & 0.5000 \\
\hline
\end{tabular}






\section{المراجع}

\section{أولاً: مراجع باللغة العربية}

مركز المعلومات ودعم اتخاذ القرار (مجلس الوزراء) (2005م)، الدين العام المحلي ومؤشر الاقتدار المالي العام.

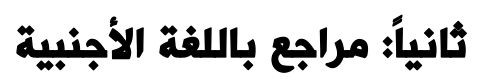

- Adedeji, O. S. (2001), "The Size and Sustainability of Nigerian Current Account Deficit", International Monetary Fund, Working Paper Series, WP No. 01/87.

- Alvarado, C., et.al. (2006), "Fiscal Sustainability in Emerging Market Countries with an Application to Ecuador", Inter-American Development Bank, WP No. 511.

- $\quad$ Artus, P. (2002), "How Has the Fiscal and External Solvency of Spain, Italy and Portugal Performed Since the Start of the Crisis", Natixis Economics Research, Working Paper No. 521, France.

- Bagnai, A. (2004), "keynesian and neoclassical fiscal sustainability indicators with applications to Emu member countries", National Bureau Of Economic Research, NBER Working paper Series No. 8057.

- Blanchard, O., et.al. (1990), "The Sustainability Of Fiscal Policy: New Answers To An Old Question", OECD Economic Studies, Working paper No.15.

- Burnside, C. (2003), "Theoretical Prerequisites for Fiscal Sustainability Analysis", manuscript University of Virginia.

- Griffoli, T. (2013), "Dynare V4 - User Guide (Public Beta Version)".

- Khadan, J. (2019), " Fiscal Sustainability in the Caribbean: An Econometric Analysis ", InterAmerican Development Bank, Working Paper Series, WP No. 1014.

- Krueger, D. (2007), "Dynamic Fiscal Policy", University of Pennsylvania - Department of Economics, First Edition, Philadelphia.

- Lee, K. and Kim, H. (2018), "Fiscal Sustainability Test on Social Spending", Review of Institution and Economics, Vol.12, No.1.

- Mendoza, E., and Oviedo, P. (2004), " Fiscal Solvency and Macroeconomic Uncertainty in Emerging Markets: The Tale of the Tormented Insurer", The Research Department Of The Inter-American Development Banks - IADB, Working paper No.153.

- Özer, M. and Coşkun, I. O. (2011), "Sustainability of Turkish fiscal deficit in the post - crisis period", Mibes Transactions International Journal, Vol.5, No.2.

- Pfeifer, J. (2013), "A Guide to Specifying Observation Equations for the Estimation of DSGE Models".

- Shastri, S., et.al. (2018), "Fiscal Sustainability in Major South Asian Economies: Evidences from Panel Data Analysis", Journal of Economic Cooperation and Development, Vol. 39, No. 2.

- Slanicay, M. (2014), "Some Notes on Historical, Theoretical, and Empirical Background of DSGE Models", Review Of Economic Perspectives, Vol.14, No.2.

- The Policy Development and Review Department (2002), "Assessing Sustainability", International Monetary Fund, Working Discussion Papers.

- Uryszek, T. (2018), "Primary Deficit Indicator, Tax Gap, and Fiscal Sustainability: Evidence from Central and Eastern EU Member States", University of Lodz, Working paper No.254, Cambridge.

- Villaverde, J. (2010), "The econometrics of DSGE models", Journal of the Spanish Economic Association, Vol.10, No.4. 